\title{
Symmetrically Normalized Instrumental-Variable Estimation Using Panel Data
}

\author{
César Alonso-BorREgo \\ Universidad Carlos III de Madrid, 28903 Getafe, Madrid, Spain (alonso1@eco.uc3m.es) \\ Manuel ARELlano \\ CEMFI, 28014 Madrid, Spain (arellano@cemfi.es)
}

\begin{abstract}
We discuss the estimation of linear panel-data models with sequential moment restrictions using symmetrically normalized generalized method of moments (GMM) estimators (SNM) and limited information maximum likelihood (LIML) analogues. These estimators are asymptotically equivalent to standard GMM but are invariant to normalization and tend to have a smaller finite-sample bias, especially when the instruments are poor. We study their properties in relation to ordinary GMM and minimum distance estimators for AR(1) models with individual effects by mean of simulations. Finally, as empirical illustrations, we estimate by SNM and LIML employment and wage equations using panels of U.K. and Spanish firms.
\end{abstract}

KEY WORDS: Autoregressive models; Dynamic panel data; Employment equations; Generalized method of moments; Monte Carlo methods; Symmetric normalization.

This work is motivated by a concern with the finitesample bias in panel data instrumental-variable (IV) estimators when the instruments are weak. A linear panel-data model with predetermined variables [like vector autoregressions (VAR's) or linear Euler equations] is typically estimated by IV techniques in first-differences using all the available lags of the predetermined variables as instruments. The specification of the equation error in first-differences reflects the fact that the analysis is conditional on an unobservable individual effect. Because the number of instruments increases with the time series dimension $(T)$, the model generates many overidentifying restrictions even for moderate values of $T$, although the quality of these instruments is often poor.

The effect of weak instruments on the distributions of two-stage least squares (2SLS) and limited information maximum likelihood (LIML) differs substantially, despite the fact that both estimators have the same asymptotic distribution. Although the distribution of LIML is centered at the parameter value, 2 SLS is biased toward ordinary least squares (OLS), and in the completely unidentified case converges to a random variable with the OLS probability limit as its central value. On the other hand, LIML has no finite moments regardless of the sample size, and as a consequence its distribution has thicker tails than that of 2SLS and a higher probability of extreme values [see Phillips (1983) for a good survey of the literature]. As a result of numerical comparisons of the two distributions involving median bias, interquartile ranges, and rates of approach to normality, Anderson, Kunitomo, and Sawa (1982) concluded that LIML was to be strongly preferred to 2SLS, particularly if the number of instruments is large. Similar conclusions emerge from the results of asymptotic approximations based on an increasing number of instruments as the sample size tends to infinity; under these sequences, LIML is a consistent estimator but 2SLS is inconsistent (Kunitomo 1980; Morimune 1983; and, more recently, Bekker 1994).
(In our context, these approximations would amount to allowing $T$ to increase to infinity at a chosen rate as opposed to the standard fixed $T$, large $N$ asymptotics.)

Despite this favorable evidence, LIML has not been used as much in applications as IV estimators. In the past, LIML was at a disadvantage relative to 2SLS on computational grounds. More fundamentally, applied econometricians have often regarded 2SLS as a more "flexible" choice than LIML from the point of view of the restrictions they were willing to impose on their models. In effect, the IV techniques used for a panel-data model with predetermined instruments are not standard 2SLS estimators because the model gives rise to a system of equations (one for each time period) with a different number of instruments available for each equation. Moreover, concern with heteroscedasticity has led to considering alternative ("two-step") generalized method of moments (GMM) estimators that use as weighting matrix more robust estimators of the variances and covariances of the orthogonality conditions (following the work of Chamberlain 1982; Hansen 1982; White 1982).

In a recent article, Hillier (1990) showed that the alternative normalization rules adopted by LIML and 2SLS are at the root of their different sampling behavior. Hillier also showed that a symmetrically normalized 2SLS estimator has properties similar to those of LIML. This result motivates our focus on symmetrically normalized estimation. Symmetrically normalized 2SLS, unlike LIML, is a GMM estimator based on structural-form orthogonality conditions, and it therefore can be readily extended to twostep weighting matrices and the nonstandard IV situations that are of interest in dynamic panel-data models, while relying on standard GMM asymptotic theory. In this article, we discuss both nonrobust and robust LIML analogues and 
symmetrically normalized GMM estimates in the panel-data context.

The symmetrically normalized estimator can be described in a simple example as follows. Consider a structural equation with a single endogenous explanatory variable and a matrix of instruments $Z$,

$$
y=\beta_{o} x+u,
$$

with associated reduced-form equations

$$
\begin{aligned}
& y=Z \pi_{o}+v_{1} \\
& x=Z \gamma_{o}+v_{2} .
\end{aligned}
$$

Both symmetrically normalized 2SLS and LIML are least squares estimators of the reduced form (2) imposing the overidentifying restrictions $\pi=\gamma \beta$. Let us define

$$
\begin{aligned}
\left(\tilde{\beta}_{V}, \tilde{\gamma}_{V}\right)= & \arg \min _{\beta, \gamma}\left(\begin{array}{c}
y-Z \gamma \beta \\
x-Z \gamma
\end{array}\right)^{\prime} \\
& \times\left(V^{-1} \otimes I\right)\left(\begin{array}{c}
y-Z \gamma \beta \\
x-Z \gamma
\end{array}\right) \\
= & \arg \min _{\beta, \gamma}\left(\begin{array}{c}
\hat{\pi}-\gamma \beta \\
\hat{\gamma}-\gamma
\end{array}\right)^{\prime} \\
& \times\left(V^{-1} \otimes Z^{\prime} Z\right)\left(\begin{array}{c}
\hat{\pi}-\gamma \beta \\
\hat{\gamma}-\gamma
\end{array}\right) .
\end{aligned}
$$

Concentrating $\gamma$ out of the least squares criterion, we obtain

$$
\tilde{\beta}_{V}=\arg \min _{\beta} \frac{(y-\beta x)^{\prime} Z\left(Z^{\prime} Z\right)^{-1} Z^{\prime}(y-\beta x)}{\left(1,-\beta^{\prime}\right) V\left(1,-\beta^{\prime}\right)^{\prime}} .
$$

LIML is $\tilde{\beta}_{V}$ with $V$ equal to the reduced-form residual covariance matrix, whereas symmetrically normalized 2SLS is $\tilde{\beta}_{V}$ with $V$ equal to an identity matrix (Malinvaud 1970; Goldberger and Olkin 1971; Keller 1975; Anderson 1976) so that both LIML and symmetrically normalized 2SLS solve minimum eigenvalue problems. Symmetrically normalized 2SLS can also be described as a GMM estimator based on the unit-length orthogonality conditions

$$
E\left[z_{i}\left(y_{i}-\beta_{o} x_{i}\right) /\left(1+\beta_{o}^{2}\right)^{1 / 2}\right]=0
$$

Note that the asymptotic distribution of $\hat{\beta}_{V}$ does not depend on the choice of $V$ because optimal minimum distance estimators (MDE) of $\beta$ based on $(\hat{\pi}-\gamma \beta, \hat{\gamma}-\gamma)$ and on $(\hat{\pi}-\hat{\gamma} \beta)$ are asymptotically equivalent. Note also that ordinary and symmetrically normalized 2SLS are given, respectively, by the ordinary and the orthogonal regressions of $\hat{y}$ on $\hat{x}(\hat{y}=Z \hat{\pi}$ and $\hat{x}=Z \hat{\gamma})$, and although the former differs from indirect 2SLS (the inverse regression of $\hat{x}$ on $\hat{y})$, the latter is invariant to normalization.

This article is organized as follows. Section 1 develops the relationship between symmetrically normalized GMM (SNM) and LIML in the context of a linear equation for panel data with sequential moment restrictions. We also present two-step SNM estimators and test statistics of overidentifying restrictions and compare them with robust LIML analogues. The latter are the "continuously up- dated GMM" estimators considered by Hansen, Heaton, and Yaron (1995). Section 2 compares the finite-sample properties of SNM and LIML to those of ordinary GMM and MDE for first-order autoregressive [AR(1)] models with individual effects. Section 3 reestimates the employment equations for a sample of U.K. firms reported by Arellano and Bond (1991) using SNM, LIML, and indirect GMM estimators. This section further illustrates the techniques by presenting symmetrically normalized estimates and bootstrap confidence intervals of employment and wage VAR's from a larger panel of Spanish firms. Finally, Section 4 concludes.

\section{SYMMETRICALLY NORMALIZED IV ESTIMATION}

Consider a model with individual effects for panel data given by

$$
\begin{aligned}
y_{i t} & =x_{i t}^{\prime} \delta_{o}+u_{i t}, \quad t=1, \ldots, T ; i=1, \ldots, N, \\
u_{i t} & =\eta_{i}+v_{i t} .
\end{aligned}
$$

The model specifies sequential moment conditions of the form $E\left(v_{i t} \mid z_{i}^{t}\right)=0$, where $z_{i}^{t}=\left(z_{i 1}^{\prime} \ldots z_{i t}^{\prime}\right)^{\prime}$ is a vector of instruments, which may include current or lagged values of $y_{i t}$ and $x_{i t}$. Thus, this setting is sufficiently general to cover models with strictly exogenous, predetermined, and endogenous explanatory variables. Observations across individuals are assumed to be independent and identically distributed.

Estimation will be based on a sequence of orthogonality conditions of the form

$$
E\left[z_{i}^{t}\left(y_{i t}^{*}-x_{i t}^{* \prime} \delta_{o}\right)\right]=0, \quad t=1, \ldots, T-1,
$$

where starred variables denote forward orthogonal deviations of the original variables (Arellano and Bover 1995). It is convenient to rewrite the transformed model as

$$
y_{i}^{*}=X_{i}^{*} \delta_{o}+u_{i}^{*}
$$

where $y_{i}^{*}=\left(y_{i 1}^{*} \ldots y_{i(T-1)}^{*}\right)^{\prime}$, and so forth.

The $k \times 1$ parameter vector $\delta_{o}$ is usually estimated by GMM leading to estimators of the form (Holtz-Eakin, Newey, and Rosen 1988; Arellano and Bond 1991; Chamberlain 1992; Arellano and Bover 1995; Ahn and Schmidt 1995)

$$
\hat{\delta}_{\mathrm{GMM}}=\left(X^{* \prime} Z A_{N} Z^{\prime} X^{*}\right)^{-1} X^{* \prime} Z A_{N} Z^{\prime} y^{*},
$$

where $y^{*}=\left(y_{1}^{* \prime} \ldots y_{N}^{* \prime}\right)^{\prime}, X^{*}=\left(X_{1}^{* \prime} \ldots X_{N}^{* \prime}\right)^{\prime}$, and $Z=$ $\left(Z_{1}^{\prime} \ldots Z_{N}^{\prime}\right)^{\prime} . Z_{i}$ is a $(T-1) \times q$ block diagonal matrix whose $t$ th block is $z_{i}^{t}$ and an optimal choice of $A_{N}$ is such that it is a consistent estimate of the inverse of $E\left(Z_{i}^{\prime} u_{i}^{*} u_{i}^{* \prime} Z_{i}\right)$. Under "classical" errors [i.e., when $E\left(v_{i t}^{2} \mid z_{i}^{t}\right) \stackrel{Z^{2}}{=} \sigma^{2}$ and $E\left(v_{i t} v_{i(t+j)} \mid z_{i}^{t}\right)=0$ for $j>0$ and all $\left.t\right], E\left(Z_{i}^{\prime} u_{i}^{*} u_{i}^{* \prime} Z_{i}\right)=$ $\sigma^{2} E\left(Z_{i}^{\prime} Z_{i}\right)$, and hence the "one-step" nonrobust choice $A_{N}=\left(\hat{\sigma}^{2} Z^{\prime} Z\right)^{-1}$ is optimal $\left(\hat{\sigma}^{2}\right.$, which denotes the residual variance, is irrelevant for estimation, but it is kept here for notational convenience). Alternatively, the standard "twostep" robust choice is $A_{N}=\left(\sum_{i} Z_{i}^{\prime} \tilde{u}_{i}^{*} \tilde{u}_{i}^{* \prime} Z_{i}\right)^{-1}$, where $\tilde{u}_{i}^{*}$ is a vector of residuals evaluated using some preliminary consistent estimate of $\delta_{o}$. Given identification, $\hat{\delta}_{\mathrm{GMM}}$ is consistent and asymptotically normal as $N \rightarrow \infty$ for 
fixed $T$. In addition, for either choice of $A_{N}$, provided the conditions under which they are optimal choices are satisfied, a consistent estimator of the asymptotic variance of $\hat{\delta}_{\mathrm{GMM}}$ is $\widehat{\operatorname{var}}\left(\hat{\delta}_{\mathrm{GMM}}\right)=\left(X^{* \prime} Z A_{N} Z^{\prime} X^{*}\right)^{-1}$. Moreover, letting $\hat{u}^{*}=y^{*}-X^{*} \hat{\delta}_{\mathrm{GMM}}$, the Sargan or GMM statistic of overidentifying restrictions is given by

$$
S=\hat{u}^{* \prime} Z A_{N} Z^{\prime} \hat{u}^{*} \stackrel{d}{\rightarrow} \chi_{q-k}^{2}
$$

Now, partition $X^{*}=\left(X_{1}^{*}, X_{2}^{*}\right)$ and $\delta_{o}=\left(\delta_{o 1}^{\prime}, \delta_{o 2}^{\prime}\right)^{\prime}$ to distinguish between nonexogenous and exogenous variables, such that the $k_{2}$ columns of $X_{2}^{*}$ are linear combinations of those of $Z$ but the $k_{1}$ columns of $X_{1}^{*}$ are not. SNM is the GMM estimator of $\delta_{o}$ based on the orthogonality conditions

$$
E \psi_{i}\left(\delta_{o}\right)=E\left[\frac{Z_{i}^{\prime}\left(y_{i}^{*}-X_{i}^{*} \delta_{o}\right)}{\left(1+\delta_{o 1}^{\prime} \delta_{o 1}\right)^{1 / 2}}\right]=0 .
$$

Because $E\left[\psi_{i}\left(\delta_{o}\right) \psi_{i}^{\prime}\left(\delta_{o}\right)\right]=E\left(Z_{i}^{\prime} u_{i}^{*} u_{i}^{* \prime} Z_{i}\right) /\left(1+\delta_{o 1}^{\prime} \delta_{o 1}\right)$, a consistent estimate of the inverse of $E\left(Z_{i}^{\prime} u_{i}^{*} u_{i}^{* \prime} Z_{i}\right)$ remains an optimal weighting matrix for the SNM estimator. Therefore,

$$
\hat{\delta}_{\mathrm{SNM}}=\arg \min _{\delta} \frac{\left(y^{*}-X^{*} \delta\right)^{\prime} M\left(y^{*}-X^{*} \delta\right)}{\left(1+\delta_{1}^{\prime} \delta_{1}\right)},
$$

where $M=Z A_{N} Z^{\prime}$. Minimizing the criterion with respect to $\delta_{2}$ we obtain a concentrated criterion that only depends on $\delta_{1}$. This gives us

$$
\begin{aligned}
\hat{\delta}_{1 \mathrm{SNM}} & =\arg \min _{\delta_{1}} d_{1}^{\prime} W_{1}^{* \prime}\left(M-M_{2}\right) W_{1}^{*} d_{1} / d_{1}^{\prime} d_{1} \\
& =\left[X_{1}^{* \prime}\left(M-M_{2}\right) X_{1}^{*}-\tilde{\lambda} I\right]^{-1} X_{1}^{* \prime}\left(M-M_{2}\right) y^{*}
\end{aligned}
$$

and

$$
\hat{\delta}_{2 \mathrm{SNM}}=\left(X_{2}^{* \prime} M X_{2}^{*}\right)^{-1} X_{2}^{* \prime} M\left(y^{*}-X_{1}^{*} \hat{\delta}_{1 \mathrm{SNM}}\right),
$$

where $W_{1}^{*}=\left(y^{*}, X_{1}^{*}\right), d_{1}=\left(1,-\delta_{1}^{\prime}\right)^{\prime}, M_{2}=M X_{2}^{*}$ $\left(X_{2}^{* \prime} M X_{2}^{*}\right)^{-1} X_{2}^{* \prime} M$, and $\tilde{\lambda}=\min$ eigen $\left[W_{1}^{* \prime}\left(M-M_{2}\right) W_{1}^{*}\right]$. Notice also that

$$
\tilde{\lambda}=\min \left(y^{*}-X^{*} \delta\right)^{\prime} M\left(y^{*}-X^{*} \delta\right) /\left(1+\delta_{1}^{\prime} \delta_{1}\right) .
$$

Equivalently,

$$
\hat{\delta}_{\mathrm{SNM}}=\left(X^{* \prime} M X^{*}-\tilde{\lambda} \Delta\right)^{-1} X^{* \prime} M y^{*}
$$

with

$$
\Delta=\left(\begin{array}{cc}
I_{k_{1}} & 0 \\
0 & 0
\end{array}\right)
$$

[if no columns of $X^{*}$ are perfectly predictable from $Z$, or if the entire vector of coefficients is normalized to unity, then $\Delta=I$ and $\tilde{\lambda}=\min$ eigen $\left(W^{* \prime} M W^{*}\right)$, with $W^{*}=$ $\left.\left(y^{*}, X^{*}\right)\right]$. In the just-identified case, $\tilde{\lambda}=0$, with the result that GMM and SNM coincide.

Because $\hat{\delta}_{\mathrm{GMM}}$ and $\hat{\delta}_{\mathrm{SNM}}$ are asymptotically equivalent, $\widehat{\operatorname{var}}\left(\hat{\delta}_{\mathrm{GMM}}\right)$ is also a consistent estimate of the asymptotic variance of $\hat{\delta}_{\mathrm{SNM}}$. An alternative natural estimator of $\operatorname{var}\left(\hat{\delta}_{\mathrm{SNM}}\right)$, however, suggested by the previous expression, is $\widehat{\operatorname{var}}\left(\hat{\delta}_{\mathrm{SNM}}\right)=\left(X^{* \prime} M X^{*}-\tilde{\lambda} \Delta\right)^{-1}$. Moreover, because $\tilde{\lambda}$ is a minimized optimal GMM criterion it can be used as an alternative test statistic of overidentifying restrictions. We have that

$$
\left(1+\hat{\delta}_{1 \mathrm{SNM}}^{\prime} \hat{\delta}_{1 \mathrm{SNM}}\right) \tilde{\lambda} \stackrel{d}{\rightarrow} \chi_{q-k}^{2},
$$

which is asymptotically equivalent to the Sargan test.

Let us now turn to consider LIML analogues or "continuously updated GMM" estimators in the terminology of Hansen et al. (1996). The nonrobust LIML analogue $\hat{\delta}_{\text {LIML1 }}$ minimizes a criterion of the form

$$
l(\delta)=\left(y^{*}-X^{*} \delta\right)^{\prime} Z A_{N}(\delta) Z^{\prime}\left(y^{*}-X^{*} \delta\right)
$$

with $A_{N}(\delta)=\left(Z^{\prime} Z\right)^{-1} /\left(y^{*}-X^{*} \delta\right)^{\prime}\left(y^{*}-X^{*} \delta\right)$. The resulting estimator is

$$
\begin{aligned}
\hat{\delta}_{\text {LIML1 }}=\left[X^{*} Z\left(Z^{\prime} Z\right)^{-1} Z^{\prime} X^{*}-\hat{l} X^{* \prime} X^{*}\right]^{-1} & \\
& \times\left[X^{* \prime} Z\left(Z^{\prime} Z\right)^{-1} Z^{\prime} y^{*}-\hat{l} X^{* \prime} y^{*}\right],
\end{aligned}
$$

where, letting $d=\left(1,-\delta^{\prime}\right)^{\prime}$,

$$
\begin{aligned}
\hat{l} & =\min d^{\prime} W^{* \prime} Z\left(Z^{\prime} Z\right)^{-1} Z^{\prime} W^{*} d /\left(d^{\prime} W^{* \prime} W^{*} d\right) \\
& =\min \text { eigen }\left[W^{* \prime} Z\left(Z^{\prime} Z\right)^{-1} Z^{\prime} W^{*}\left(W^{* \prime} W^{*}\right)^{-1}\right] .
\end{aligned}
$$

On the other hand, the robust LIML analogue $\hat{\delta}_{\text {LIML2 }}$ minimizes a criterion of the same form as (18) with

$$
A_{N}(\delta)=\left(\sum_{i=1}^{N} Z_{i}^{\prime} u_{i}^{*}(\delta) u_{i}^{*}(\delta)^{\prime} Z_{i}\right)^{-1},
$$

where $u_{i}^{*}(\delta)=y_{i}^{*}-X_{i}^{*} \delta$. Therefore, LIML2, unlike LIML1 or the SNM estimators, does not solve a simple minimum eigenvalue problem and requires the use of numerical optimization methods.

Both the SNM and the LIML analogues are invariant to normalization, but the ordinary GMM estimator is not. That is, if the equation is solved for an endogenous variable other than $y_{i}$, contrary to the case with ordinary GMM, the indirect estimates obtained from SNM or LIML analogues coincide with the direct SNM or LIML estimates, respectively. [Notice that empirical likelihood estimators of the type considered by Qin and Lawless (1994) and Imbens (1997) will also be invariant to normalization due to the invariance property of maximum likelihood estimators.]

Symmetrically normalized estimators are potentially attractive alternatives to ordinary GMM on at least two grounds (aside from the desirability of invariance to normalization in its own right). First, they tend to have a smaller finite-sample bias than the GMM estimators. Hillier (1990) showed that, for the normal case in a standard linear structural equation with two endogenous variables, symmetrically normalized 2SLS and LIML are "spherically unbiased" in finite samples [meaning that the density of $\hat{a}=\hat{d}_{1} /\left(\hat{d}_{1}^{\prime} \hat{d}_{1}\right)^{1 / 2}$ defined on the unit circle is symmetric about the true points $\pm a= \pm d_{1} /\left(d_{1}^{\prime} d_{1}\right)^{1 / 2}$ having modes at $\pm a]$. However, 2SLS does not have this property.

Second, the concentration of the densities of the symmetrically normalized estimators depends on the quality of the instruments. In the completely unidentified case, as shown by Hillier, these estimators have a uniform distribution on 
the unit circle. This is in contrast with 2SLS, which converges to the same limit as OLS and whose distribution is determined exclusively by the normalization adopted. When the instruments are poor, as well as when the number of instruments is large relative to the sample size, 2SLS tends to provide results that are biased in the direction of OLS and also large discrepancies between "direct" and "indirect" 2SLS when using different normalizations. This situation has been stressed in several recent works (Bekker 1994; Bound, Jaeger, and Baker 1995; Angrist and Krueger 1995; Staiger and Stock 1997, among others). In contrast, with poor instruments the distributions of LIML and symmetrically normalized 2 SLS accurately reproduce the fact that the information on the structural parameters is very small.

Although the LIML analogues and the SNM estimators are asymptotically equivalent (and in the Hillier setting exhibit similar finite-sample properties as well), SNM has some disadvantages relative to the other estimators. The main one is that in general the results are not independent of the units in which the variables are measured, so that a sensible choice of units may be important. In contrast, ordinary GMM is invariant to units but not to normalization, and LIML is invariant to units and normalization. This problem does not arise in the autoregressive panel-data models

Table 1. Model 1: Nonrobust Estimates

\begin{tabular}{|c|c|c|c|c|c|c|c|}
\hline & & \multicolumn{3}{|c|}{$\alpha=.5$} & \multicolumn{3}{|c|}{$\alpha=.8$} \\
\hline & & GMM1 & SNM1 & LIML1 & GMM1 & SNM1 & $L I M L 1$ \\
\hline \multicolumn{8}{|c|}{$T=4$} \\
\hline \multirow{5}{*}{$\sigma_{\eta}^{2}=0$} & Median & .49 & .50 & .50 & .76 & .80 & .80 \\
\hline & $\%$ bias & 2.5 & .3 & .6 & 5.6 & .1 & .1 \\
\hline & iqr & .18 & .19 & .19 & .28 & .29 & .29 \\
\hline & iq80 & .35 & .36 & .36 & .56 & .61 & .61 \\
\hline & MAE & .09 & .09 & .09 & .15 & .15 & .15 \\
\hline \multirow[t]{5}{*}{$\sigma_{\eta}^{2}=.2$} & Median & .47 & .49 & .49 & .66 & .77 & .77 \\
\hline & $\%$ bias & 6.9 & 1.7 & 1.7 & 17.8 & 3.7 & 4.1 \\
\hline & iqr & .23 & .25 & .24 & .45 & .57 & .58 \\
\hline & iq80 & .44 & .47 & .47 & .93 & 1.26 & 1.29 \\
\hline & MAE & .12 & .12 & .12 & .25 & .28 & .29 \\
\hline \multirow{6}{*}{$\sigma_{\eta}^{2}=1$} & Median & .43 & .48 & .48 & .44 & .65 & .61 \\
\hline & $\%$ bias & 14.8 & 3.8 & 3.1 & 44.7 & 19.0 & 23.8 \\
\hline & iqr & .33 & .36 & .36 & .67 & .95 & 1.02 \\
\hline & iq80 & .68 & .77 & .77 & 1.39 & 2.81 & 2.89 \\
\hline & MAE & .18 & .18 & .18 & .44 & .50 & .53 \\
\hline & \multicolumn{7}{|c|}{$T=7$} \\
\hline \multirow{5}{*}{$\sigma_{\eta}^{2}=0$} & Median & .47 & .50 & .49 & .75 & .80 & .79 \\
\hline & $\%$ bias & 5.0 & .7 & 2.0 & 6.0 & .3 & 1.1 \\
\hline & iqr & .09 & .09 & .09 & .11 & .12 & .12 \\
\hline & iq80 & .16 & .17 & .17 & .22 & .23 & .24 \\
\hline & MAE & .05 & .04 & .04 & .07 & .06 & .06 \\
\hline \multirow{5}{*}{$\sigma_{\eta}^{2}=.2$} & Median & .47 & .50 & .49 & .70 & .81 & .78 \\
\hline & $\%$ bias & 6.7 & .8 & 1.8 & 13.0 & 1.2 & 2.7 \\
\hline & iqr & .11 & .11 & .11 & .18 & .18 & .21 \\
\hline & iq80 & .20 & .21 & .21 & .34 & .39 & .45 \\
\hline & MAE & .06 & .06 & .06 & .12 & .09 & .11 \\
\hline \multirow[t]{5}{*}{$\sigma_{\eta}^{2}=1$} & Median & .45 & .50 & .48 & .61 & .82 & .74 \\
\hline & $\%$ bias & 10.4 & 1.0 & 3.3 & 24.0 & 3.0 & 8.1 \\
\hline & iqr & .13 & .14 & .14 & .23 & .26 & .38 \\
\hline & iq80 & .24 & .26 & .27 & .45 & .54 & .86 \\
\hline & MAE & .07 & .07 & .07 & .20 & .13 & .19 \\
\hline
\end{tabular}

NOTE: 1,000 replications. $N=100, \sigma_{v}^{2}=1 . \%$ bias gives the percentage median bias for al the estimates; iqr is the 75th-25th interquartile range; iq80 is the 90th-10th interquantile range MAE denotes the median absolute error. discussed later because in that case the SNM estimator is invariant to units and to normalization (just because in the autoregressive case a change in the units of the right-side variable leads trivially to a similar change in the units of the left-side variable). Another disadvantage of SNM is that the distinction between exogenous and nonexogenous variables is relevant for the specification of the estimator. This is so because in the case of SNM only the length of the coefficient vector for the nonexogenous variables is normalized to unity, and, contrary to LIML, this differs from normalizing to unity the entire coefficient vector. SNM, however, does have a computational advantage over LIML when we consider two-step or robust estimators. Indeed, LIML2, or continuously updated GMM, no longer solves a minimum eigenvalue problem, whereas two-step SNM only involves simple calculations that are similar to those performed for two-step ordinary GMM. Of course, SNM is limited to linear models, but in such context it is of interest to see if SNM, which is considerably faster and simpler than LIML2, can provide the benefits of the more complicated estimators and perhaps avoid problems of nonconvergence in the case of LIML2.

\section{EXPERIMENTAL COMPARISONS}

The purpose of this section is to study the finite-sample properties of the symmetrically normalized estimators considered previously in relation to ordinary GMM for an AR(1) model with individual effects. The IV restrictions implied by various versions of the model can be represented as simple structures on the covariance matrix of the data, so we can also make comparisons with the MDE of these covariance structures. The emphasis is not on assessing the value of enforcing particular restrictions in the model, as done, for example, by Ahn and Schmidt (1995), Arellano and Bover (1995), and Blundell and Bond (1998). Rather, we wish to evaluate the effects in small samples of using alternative estimating criteria that produce asymptotically equivalent estimators for fixed $T$ and large $N$. We concentrate on a random-effects AR(1) model because of its simplicity and the fact that it is a case that has received much attention in the literature.

\subsection{Models and Estimators}

Let us consider a random sample of individual time series of size $T, y_{i}^{T}=\left(y_{i 1}, \ldots, y_{i T}\right)^{\prime}(i=1, \ldots, N)$ with secondorder moment matrix $E\left(y_{i}^{T} y_{i^{\prime}}^{T}\right)=\Omega=\left\{\omega_{t s}\right\}$. We assume that the joint distribution of $y_{i}^{T}$ and the unobservable timeinvariant effect $\eta_{i}$ satisfies Assumption A:

$$
\begin{gathered}
y_{i t}=\alpha y_{i(t-1)}+\eta_{i}+v_{i t}, \quad t=2, \ldots, T, \\
E\left(v_{i t} \mid y_{i}^{t-1}\right)=0,
\end{gathered}
$$

where $E\left(\eta_{i}\right)=\gamma, E\left(v_{i t}^{2}\right)=\sigma_{t}^{2}$, and $\operatorname{var}\left(\eta_{i}\right)=\sigma_{\eta}^{2}$.

Notice that the dependence between $\eta_{i}$ and $v_{i t}$ is not restricted by Assumption A, nor is the possibility of conditional heteroscedasticity ruled out, because $E\left(v_{i t}^{2} \mid y_{i}^{t-1}\right)$ need not coincide with $\sigma_{t}^{2}$.

Following Arellano and Bond (1991), Assumption A implies $(T-2)(T-1) / 2$ linear moment restrictions of the 
form

$$
E\left[y_{i}^{t-2}\left(\Delta y_{i t}-\alpha \Delta y_{i(t-1)}\right)\right]=0 .
$$

These restrictions can also be represented as constraints on the elements of $\Omega$. Multiplying (22) by $y_{i s}$ for $s<t$ and taking expectations gives $\omega_{t s}=\alpha \omega_{(t-1) s}+c_{s}(t=$ $2, \ldots T ; s=1, \ldots, t-1)$, where $c_{s}=E\left(y_{i s} \eta_{i}\right)$. This means that, given Assumption A, the $T(T+1) / 2$ different elements of $\Omega$ can be written as functions of the $2 T \times 1$ parameter vector $\theta=\left(\alpha, c_{1}, \ldots, c_{T-1}, \omega_{11}, \ldots, \omega_{T T}\right)^{\prime}$.

We call this moment structure Model 1. Because it is a special case of the model in Section 1, all the estimators discussed in Section 1 can be particularized to the present case. Here, however, we express the IV restrictions using errors in first-differences as opposed to orthogonal deviations to simplify the mapping with covariance structures. Notice that with $T=3$ the parameters $\left(\alpha, c_{1}, c_{2}\right)$ are just-identified as functions of the elements of $\Omega$.

The orthogonality conditions (24) are the only restrictions implied by Assumption A on the second-order moments of the data. They are not the only restrictions available, however, because (23) also implies that nonlinear functions of $y_{i}^{t-2}$ are uncorrelated with $\Delta v_{i t}$. The semiparametric efficiency bound for this model can be obtained from the results of Chamberlain (1992). One reason estimators based on (24) may not be fully efficient asymptotically is that the dependence between $\eta_{i}$ and $y_{i}^{T}$ may be nonlinear. Another reason would be unaccounted conditional heteroscedasticity.

Model 1 is attractive because it is based on minimal assumptions. We may be willing to impose additional structure, however, if this conforms to a priori beliefs. One possibility is to assume that the errors $v_{i t}$ are mean independent of the individual effect $\eta_{i}$ given $y_{i}^{t-1}$. This situation gives rise to Assumption $\mathrm{A}^{\prime}$ :

$$
E\left(v_{i t} \mid y_{i}^{t-1}, \eta_{i}\right)=0 .
$$

Note that Assumption $A^{\prime}$ is more restrictive than Assumption $\mathrm{A}$. When $T \geq 4$, Assumption $\mathrm{A}^{\prime}$ implies the following additional $T-3$ moment restrictions:

$$
\begin{aligned}
E\left[\left(y_{i t}-\alpha y_{i(t-1)}\right)\left(\Delta y_{i(t-1)}-\alpha \Delta y_{i(t-2)}\right)\right] & =0, \\
t & =4, \ldots, T .
\end{aligned}
$$

In effect, we can write $E\left[\left(y_{i t}-\alpha y_{i(t-1)}-\eta_{i}\right)\left(\Delta y_{i(t-1)}-\right.\right.$ $\left.\left.\alpha \Delta y_{i(t-2)}\right)\right]=0$ and, because $E\left(\eta_{i} \Delta v_{i(t-1)}\right)=0$, the result follows.

GMM estimators of $\alpha$ that exploit these restrictions in ad-

\begin{tabular}{|c|c|c|c|c|c|c|c|c|c|}
\hline & & \multicolumn{4}{|c|}{$\alpha=.5$} & \multicolumn{4}{|c|}{$\alpha=.8$} \\
\hline & & GMM2 & SNM2 & LIML2 & $M D E$ & GMM2 & SNM2 & $L I M L 2$ & $M D E$ \\
\hline \multicolumn{10}{|c|}{$T=4$} \\
\hline \multirow[t]{5}{*}{$\sigma_{\eta}^{2}=0$} & Median & .49 & .50 & .51 & .51 & .76 & .80 & .81 & .80 \\
\hline & $\%$ bias & 2.1 & .2 & 1.6 & 2.1 & 4.9 & .3 & 1.7 & .0 \\
\hline & iqr & .19 & .19 & .19 & .12 & .29 & .30 & .31 & .10 \\
\hline & iq80 & .36 & .38 & .38 & .23 & .58 & .62 & .63 & .21 \\
\hline & MAE & .09 & .09 & .09 & .06 & .15 & .15 & .16 & .05 \\
\hline \multirow{5}{*}{$\sigma_{\eta}^{2}=.2$} & Median & .47 & .49 & .50 & .51 & .65 & .76 & .84 & .71 \\
\hline & $\%$ bias & 6.5 & 1.8 & .3 & 1.3 & 19.0 & 4.6 & 5.1 & 11.3 \\
\hline & iqr & .24 & .25 & .25 & .20 & .47 & .55 & .56 & .28 \\
\hline & iq80 & .47 & .50 & .51 & .39 & .97 & 1.33 & 1.23 & .58 \\
\hline & MAE & .12 & .13 & .13 & .10 & .27 & .28 & .28 & .11 \\
\hline \multirow{6}{*}{$\sigma_{\eta}^{2}=1$} & Median & .44 & .47 & .50 & .49 & .45 & .64 & .82 & .65 \\
\hline & $\%$ bias & 12.8 & 5.4 & .5 & 2.2 & 43.6 & 19.5 & 2.9 & 19.1 \\
\hline & iqr & .35 & .38 & .38 & .82 & .70 & 1.03 & .94 & .48 \\
\hline & iq80 & .75 & .80 & .80 & .56 & 1.53 & 2.82 & 2.22 & .94 \\
\hline & MAE & .18 & .19 & .19 & .16 & .46 & .54 & .47 & .18 \\
\hline & & & & $T=7$ & & & & & \\
\hline \multirow[t]{5}{*}{$\sigma_{\eta}^{2}=0$} & Median & .48 & .50 & .50 & .51 & .75 & .79 & .80 & .81 \\
\hline & $\%$ bias & 4.3 & .4 & .6 & 2.0 & 5.7 & .8 & .1 & 1.4 \\
\hline & iqr & .10 & .10 & .10 & .09 & .13 & .13 & .14 & .10 \\
\hline & iq80 & .18 & .19 & .21 & .17 & .24 & .25 & .28 & .17 \\
\hline & MAE & .05 & .05 & .05 & .04 & .07 & .07 & .07 & .05 \\
\hline \multirow{5}{*}{$\sigma_{\eta}^{2}=.2$} & Median & .47 & .50 & .50 & .50 & .69 & .79 & .81 & .74 \\
\hline & $\%$ bias & 6.2 & .5 & .4 & .1 & 13.7 & 1.7 & .9 & 7.8 \\
\hline & iqr & .12 & .12 & .13 & .12 & .20 & .20 & .24 & .17 \\
\hline & iq80 & .23 & .23 & .26 & .23 & .39 & .41 & .51 & .34 \\
\hline & MAE & .06 & .06 & .06 & .06 & .13 & .10 & .12 & .09 \\
\hline \multirow[t]{5}{*}{$\sigma_{\eta}^{2}=1$} & Median & .45 & .49 & .50 & .50 & .59 & .77 & .80 & .71 \\
\hline & $\%$ bias & 9.8 & 1.5 & .0 & .2 & 26.0 & 3.9 & .1 & 11.1 \\
\hline & iqr & .14 & .15 & .16 & .15 & .27 & .28 & .36 & .22 \\
\hline & iq80 & .28 & .30 & .33 & .29 & .53 & .59 & .80 & .46 \\
\hline & MAE & .08 & .07 & .08 & .08 & .22 & .15 & .18 & .11 \\
\hline
\end{tabular}
dition to those in (24) were considered by Ahn and Schmidt (1995), but because the additional restrictions are nonlinear

Table 2. Model 1: Robust Estimates

NOTE: See note to Table 1. 
we do not simulate them here. An alternative representation of the restrictions in (26) is in terms of a recursion of the coefficients $c_{t}$ introduced previously. Multiplying (22) by $\eta_{i}$ and taking expectations gives $c_{t}=\alpha c_{t-1}+\phi(t=2, \ldots, T)$, where $\phi=\gamma^{2}+\sigma_{\eta}^{2}=E\left(\eta_{i}^{2}\right)$ so that $c_{1} \ldots c_{T-1}$ can be written in terms of $c_{1}$ and $\phi$. This gives rise to a covariance structure in which $\Omega$ depends on the $(T+3) \times 1$ parameter vector $\theta=\left(\alpha, \phi, c_{1}, \omega_{11}, \ldots, \omega_{T T}\right)^{\prime}$. Notice that with $T=3$ Assumption $\mathrm{A}^{\prime}$ does not imply further restrictions in $\Omega$, with the result that $\alpha$ remains just-identified relative to the second-order moments.

Other forms of additional structure that can be imposed are various versions of mean or variance stationarity conditions. Assumption $\mathrm{B}$, which requires the change in $y_{i t}$ to be mean independent of the individual effect $\eta_{i}$, is a particularly useful mean stationarity condition:

$$
E\left(y_{i t}-y_{i(t-1)} \mid \eta_{i}\right)=0, \quad t=2, \ldots, T .
$$

Notice that, given Assumption A, Assumption B implies that $E\left(y_{i t}\right)=\gamma /(1-\alpha)$. Relative to Assumption A and Model 1, Assumption B adds the following $(T-2)$ moment restrictions on $\Omega$ :

$$
E\left[\left(y_{i t}-\alpha y_{i(t-1)}\right) \Delta y_{i(t-1)}\right]=0, \quad t=3, \ldots, T,
$$

which were proposed by Arellano and Bover (1995), who developed a linear GMM estimator of $\alpha$ on the basis of (24) and (28). Relative to Assumption $\mathrm{A}^{\prime}$, however, Assumption $B$ only adds one moment restriction, which can be written as $E\left[\left(y_{i 3}-\alpha y_{i 2}\right) \Delta y_{i 2}\right]=0$. In terms of the parameters $c_{t}$, the implication of Assumption $\mathrm{B}$ is that $c_{1}=\cdots=c_{T-1}$ if we move from Assumption $\mathrm{A}$ or that $c_{1}=\phi /(1-\alpha)$ if we move from Assumption $\mathrm{A}^{\prime}$. This gives rise to Model 2 , in which $\Omega$ depends on the $(T+2) \times 1$ parameter vector $\theta=\left(\alpha, \phi, \omega_{11}, \ldots, \omega_{T T}\right)^{\prime}$. Notice that with $T=3, \alpha$ is overidentified under Assumption B.

The basic specification can be restricted further in various ways. For example, we could consider time series homoscedasticity of the form $E\left(v_{i t}^{2}\right)=\sigma^{2}$ for $t=2, \ldots, T$ and stationarity of the variance of the initial conditions. The combination of these assumptions with the previous ones would give rise to additional models, some of which were discussed in detail by Ahn and Schmidt (1995). In the simulations, however, we concentrate on Models 1 and 2 because they embody linear IV restrictions that have been found most useful in applications. Although for Model 1 we shall simulate the robust and nonrobust estimators discussed in Section 1, for Model 2 we shall only report robust estimates - that is, the Arellano and Bover (1995) GMM estimator and its symmetrically normalized and continuously

\begin{tabular}{|c|c|c|c|c|c|c|c|c|c|}
\hline & & \multicolumn{4}{|c|}{$\alpha=.5$} & \multicolumn{4}{|c|}{$\alpha=.8$} \\
\hline & & GMM2 & SNM2 & $L I M L 2$ & $M D E$ & GMM2 & SNM2 & $L I M L 2$ & $M D E$ \\
\hline \multicolumn{10}{|c|}{$T=4$} \\
\hline \multirow[t]{5}{*}{$\sigma_{\eta}^{2}=0$} & Median & .50 & .51 & .51 & .51 & .79 & .81 & .81 & .81 \\
\hline & $\%$ bias & .8 & 2.0 & 1.9 & 1.2 & .9 & 1.5 & 1.7 & .7 \\
\hline & iqr & .15 & .15 & .15 & .07 & .17 & .17 & .17 & .05 \\
\hline & iq80 & .28 & .28 & .29 & .14 & .32 & .31 & .33 & .09 \\
\hline & MAE & .07 & .07 & .08 & .03 & .08 & .08 & .09 & .02 \\
\hline \multirow{5}{*}{$\sigma_{\eta}^{2}=.2$} & Median & .50 & .51 & .51 & .51 & .79 & .82 & .81 & .81 \\
\hline & $\%$ bias & .9 & 2.5 & 1.9 & 1.8 & .7 & 2.7 & 1.5 & 1.3 \\
\hline & iqr & .17 & .17 & .19 & .19 & .20 & .19 & .22 & .21 \\
\hline & iq80 & .31 & .32 & .33 & .33 & .37 & .36 & .40 & .36 \\
\hline & MAE & .09 & .09 & .09 & .09 & .10 & .10 & .11 & .10 \\
\hline \multirow{6}{*}{$\sigma_{\eta}^{2}=1$} & Median & .52 & .54 & .51 & .51 & .85 & .87 & .81 & .82 \\
\hline & $\%$ bias & 3.1 & 8.4 & 1.93 & 2.3 & 5.7 & 9.2 & 1.0 & 2.1 \\
\hline & iqr & .19 & .20 & .21 & .21 & .19 & .18 & .25 & .22 \\
\hline & iq80 & .36 & .37 & .39 & .39 & .38 & .37 & .43 & .40 \\
\hline & MAE & .09 & .10 & .11 & .11 & .11 & .11 & .12 & .10 \\
\hline & & & & $T=7$ & & & & & \\
\hline \multirow[t]{5}{*}{$\sigma_{\eta}^{2}=0$} & Median & .49 & .50 & .50 & .51 & .78 & .80 & .80 & .80 \\
\hline & $\%$ bias & 2.9 & .1 & .6 & 1.2 & 3.0 & .5 & 6 & .4 \\
\hline & iqr & .08 & .08 & .09 & .06 & .09 & .08 & .09 & .04 \\
\hline & iq80 & .15 & .16 & .17 & .11 & .17 & .16 & .18 & .08 \\
\hline & MAE & .04 & .04 & .04 & .03 & .05 & .04 & .05 & .02 \\
\hline \multirow{5}{*}{$\sigma_{\eta}^{2}=.2$} & Median & .49 & .50 & .50 & .50 & .78 & .80 & .81 & .81 \\
\hline & $\%$ bias & 2.6 & .9 & .6 & .6 & 2.4 & .5 & 1.1 & 1.1 \\
\hline & iqr & .09 & .09 & .10 & .10 & .11 & .10 & .12 & .12 \\
\hline & iq80 & .18 & .18 & .20 & .20 & .20 & .19 & .22 & .22 \\
\hline & MAE & .05 & .05 & .05 & .05 & .05 & .05 & .06 & .06 \\
\hline \multirow[t]{5}{*}{$\sigma_{\eta}^{2}=1$} & Median & .50 & .51 & .50 & .50 & .83 & .85 & .81 & .81 \\
\hline & $\%$ bias & .7 & 2.9 & .2 & .4 & 3.5 & 5.7 & .7 & 1.8 \\
\hline & iqr & .10 & .11 & .11 & .11 & .12 & .11 & .14 & .13 \\
\hline & iq80 & .19 & .20 & .22 & .22 & .22 & .21 & .25 & .25 \\
\hline & MAE & .05 & .05 & .05 & .05 & .07 & .07 & .07 & .07 \\
\hline
\end{tabular}

Table 3. Model 2: Robust Estimates

NOTE: See note to Table 1 
updated counterparts. We do so because the combined set of moments in (24) and (28) lack a sequential structure, with the result that there is no simple optimal one-step estimator under "classical" errors.

The coefficient $\alpha$ together with the other free parameters in the covariance structure representations of the previous models can be jointly estimated by MD on the basis of the matrix of sample second-order moments $\hat{\Omega}=$ $N^{-1} \sum_{i=1}^{N} y_{i}^{T} y_{i}^{T^{\prime}}$. Such estimates have the same asymptotic distribution as the corresponding GMM estimators but may be cumbersome in more general conditional models because they need to solve a nonlinear optimization problem over a larger parameter space. It is of some interest, however, to compare their finite-sample performance with the SNM and LIML estimates of the random effects AR(1) model. Optimal MDE minimize a criterion of the form

$$
c_{d}(\theta)=[\hat{\omega}-\omega(\theta)]^{\prime} V_{N}^{-1}[\hat{\omega}-\omega(\theta)],
$$

where $V_{N}=N^{-1} \sum_{i=1}^{N} w_{i} w_{i}^{\prime}-\hat{\omega} \hat{\omega}^{\prime}, \hat{\omega}=\operatorname{vech}(\hat{\Omega})$ denotes the $T(T+1) / 2$ vector containing the elements in the upper triangle of $\hat{\Omega}$, and similarly $\omega(\theta)=\operatorname{vech}[\Omega(\theta)]$ and $\omega_{i}=$ $\operatorname{vech}\left(y_{i}^{T} y_{i}^{T-1^{\prime}}\right)$.

\subsection{Monte Carlo Results}

An important issue is how instrument quality affects the estimators. In Model 1, this depends on the values of $\alpha$ and $r=\sigma_{\eta}^{2} / \sigma^{2}$. To see this, note that under stationarity the correlation between $\Delta y_{t-1}$ and $y_{t-2}$ is $\rho=-(1-\alpha)[2(1-$ $\alpha+(1+\alpha) r)]^{-1 / 2}$, which is decreasing in $\alpha$ and $r$. For this reason, we exclude from the simulations models with small values of $\alpha$, which can be expected to perform relatively well. We consider cases with $\alpha=.5, .8 ; \sigma_{\eta}^{2}=0, .2,1 ; T=$ 4,7 ; and $N=100$. The variance of the random error $\sigma^{2}$ is kept equal to unity for all cases. For each experiment, we generated 1,000 samples of $N$ independent observations of $\left(y_{i 1}, \ldots, y_{i T}\right)$ from the process

$$
y_{i 1}=(1-\alpha)^{-1} \eta_{i}+\left(1-\alpha^{2}\right)^{-1 / 2} v_{i 1}
$$

and

$$
y_{i t}=\alpha y_{i(t-1)}+\eta_{i}+v_{i t}, \quad t=2, \ldots, T,
$$

with $v_{i}=\left(v_{i 1}, \ldots, v_{i T}\right)^{\prime} \sim \mathrm{N}(0, I)$ and $\eta_{i} \sim \mathrm{N}\left(0, \sigma_{\eta}^{2}\right)$ independent of $v_{i}$.

Tables 1 and 2 (pp. 39-40) report sample medians, percentage biases, interquantile ranges, and median absolute errors (MAE's) for GMM, SNM, and LIML estimators for Model 1 (means and standard deviations are not reported because the symmetrically normalized estimators can be expected to have infinite moments). Table 1 contains the results for the nonrobust estimators and Table 2 for the robust ones. Table 2 also reports the results for the MDE, which is also robust. Whereas LIML2 and MDE are one-step estimators, however, GMM2 and SNM2 are calculated in two steps. The weighting matrices of GMM2 and SNM2 are based on GMM1 residuals. SNM1 and LIML1 always have a smaller bias and a larger dispersion than GMM1. When

\begin{tabular}{|c|c|c|c|c|c|c|c|c|c|c|c|c|}
\hline & \multicolumn{6}{|c|}{$T=4$} & \multicolumn{6}{|c|}{$T=7$} \\
\hline & \multicolumn{3}{|c|}{$\alpha=.5$} & \multicolumn{3}{|c|}{$\alpha=.8$} & \multicolumn{3}{|c|}{$\alpha=.5$} & \multicolumn{3}{|c|}{$\alpha=.8$} \\
\hline & GMM1 & SNM1 & $L I M L 1$ & GMM1 & SNM1 & $L I M L 1$ & GMM1 & SNM1 & $L I M L 1$ & GMM1 & SNM1 & $L I M L 1$ \\
\hline & & & & & & $\sigma_{\eta}^{2}=0$ & & & & & & \\
\hline .05 & -1.97 & -1.84 & -1.87 & -2.16 & -1.90 & -2.03 & -2.04 & -1.66 & -1.84 & -2.26 & -1.62 & -1.95 \\
\hline .10 & -1.54 & -1.42 & -1.44 & -1.74 & -1.46 & -1.56 & -1.65 & -1.27 & -1.46 & -1.87 & -1.25 & -1.51 \\
\hline .25 & -.86 & -.74 & -.75 & -.98 & -.73 & -.78 & -1.01 & -.64 & -.79 & -1.23 & -.61 & -.82 \\
\hline .50 & -.13 & -.02 & -.01 & -.25 & .00 & -.01 & -.32 & .04 & -.08 & -.53 & .06 & -.07 \\
\hline .75 & .53 & .62 & .64 & .41 & .59 & .64 & .37 & .74 & .64 & .17 & .73 & .68 \\
\hline .90 & 1.08 & 1.17 & 1.22 & .93 & 1.06 & 1.15 & .98 & 1.33 & 1.26 & .75 & 1.29 & 1.30 \\
\hline \multirow[t]{2}{*}{.95} & 1.41 & 1.48 & 1.53 & 1.20 & 1.30 & 1.41 & 1.33 & 1.70 & 1.65 & 1.10 & 1.61 & 1.67 \\
\hline & & & & & & $\sigma_{\eta}^{2}=.2$ & & & & & & \\
\hline .05 & -2.05 & -1.89 & -1.95 & -2.39 & -2.00 & -2.38 & -2.12 & -1.65 & -1.92 & -2.51 & -1.57 & -2.35 \\
\hline .10 & -1.63 & -1.47 & -1.52 & -1.95 & -1.55 & -1.88 & -1.74 & -1.27 & -1.51 & -2.13 & -1.19 & -1.86 \\
\hline .25 & -.91 & -.77 & -.79 & -1.22 & -.79 & -.99 & -1.08 & -.63 & -.82 & -1.51 & -.56 & -1.02 \\
\hline .50 & -.18 & -.04 & -.03 & -.44 & -.03 & -.06 & -.39 & .06 & -.10 & -.81 & .09 & -.13 \\
\hline .75 & .48 & .61 & .64 & .25 & .47 & .64 & .30 & .73 & .62 & -.12 & .69 & .71 \\
\hline .90 & 1.03 & 1.13 & 1.19 & .71 & .82 & 1.07 & .90 & 1.33 & 1.27 & .48 & 1.19 & 1.43 \\
\hline \multirow[t]{2}{*}{.95} & 1.33 & 1.42 & 1.50 & .92 & .99 & 1.27 & 1.24 & 1.65 & 1.61 & .80 & 1.47 & 1.79 \\
\hline & & & & & & $\sigma_{\eta}^{2}=1$ & & & & & & \\
\hline .05 & -2.20 & -1.98 & -2.13 & -2.68 & -2.16 & -2.83 & -2.19 & -1.62 & -2.03 & -2.74 & -1.47 & -3.18 \\
\hline .10 & -1.74 & -1.52 & --1.64 & -2.20 & -1.64 & -2.30 & -1.83 & -1.25 & -1.62 & -2.40 & -1.11 & -2.66 \\
\hline .25 & -1.04 & -.81 & -.88 & -1.52 & -.89 & -1.46 & -1.18 & -.61 & -.91 & -1.79 & -.51 & -1.52 \\
\hline .50 & -.27 & -.05 & -.05 & -.74 & -.12 & -.39 & -.49 & .07 & -.13 & -1.10 & .12 & -.28 \\
\hline .75 & .40 & .57 & .66 & -.01 & .27 & .55 & .20 & .73 & .62 & -.40 & .65 & .85 \\
\hline .90 & .91 & 1.00 & 1.16 & .46 & .56 & .95 & .79 & 1.29 & 1.27 & .20 & 1.05 & 1.69 \\
\hline .95 & 1.17 & 1.23 & 1.41 & .65 & .71 & 1.17 & 1.11 & 1.61 & 1.63 & .49 & 1.27 & 2.10 \\
\hline
\end{tabular}
$\sigma_{\eta}^{2}=0$, all estimators perform well, but when $\sigma_{\eta}^{2}=.2$

Table 4. Model 1: Nonrobust Estimates, Quantiles of the $t$ Statistics

NOTE: 10,000 replications. $N=100, \sigma_{v}^{2}=1$. The 5 th, 10 th, 25 th, 50 th, 75 th, 90 th, and 95 th quantiles for the standard normal distribution are, respectively, $-1.64,-1.28,-.67,0, .67,1.28$ and 1.64 
or 1 , the differences in the distributions of GMM1 and the symmetrically normalized estimators become apparent: The higher $\sigma_{\eta}^{2}$ or $\alpha$, the larger the negative bias of GMM1 for a given $T$, whereas SNM1 remains essentially median unbiased. The behavior of LIML1 is similar to that of SNM1, although in some cases it shows somewhat larger biases and dispersion. SNM1 and LIML1 have a larger interquartile range than GMM1, but the differences are small except in the almost unidentified cases (with $\alpha=.8$ and $T=4$ ). The MAE's of the three estimators are of a similar magnitude, although those for GMM1 tend to be smaller than those for SNM1 or LIML1 with $T=4$ and larger with $T=7$.

Turning to Table 2, GMM2 and SNM2 exhibit a very similar behavior to GMM1 and SNM1, respectively. LIML2, which is the robust continuously updated GMM estimator, is virtually median unbiased in all the experiments, although it tends to have a larger MAE than SNM2. LIML2 was calculated by numerical optimization, and we found some instances of nonconvergence. Out of 1,000 replications, we found 86 cases of nonconvergence for the experiment with $\alpha=.8, \sigma_{\eta}^{2}=1$, and $T=4$, and 7 cases in each of the experiments with $\alpha=.8, \sigma_{\eta}^{2}=.2, T=4$, and $\alpha=.8, \sigma_{\eta}^{2}=1, T=7$.

The MDE has a smaller interquartile range than GMM2, SNM2, or LIML2, a difference that is especially noticeable for $T=4$ (with $\sigma_{\eta}^{2}=0$ and $\alpha=.8$, the interquartile range of the MDE is about three times smaller than that of the other estimators). As far as median bias is concerned, the MDE is practically unbiased when $\alpha=.5$, but exhibits some larger biases when $\sigma_{\eta}^{2}$ is not 0 and $\alpha=.8$. In com- mon with LIML2, however, we also found several cases of nonconvergence for MDE, with all the cases arising almost exclusively in the experiments with $\alpha=.8$. Specifically, with $\alpha=.8$ and $T=4$, we encountered 36, 46, and 86 cases of nonconvergence for $\sigma_{\eta}^{2}=0, .2$, and 1 , respectively, whereas, with $T=7$, the number of cases, given in the same order, were 22,35 , and 118 .

With $T=7$, Tables 1 and 2 clearly indicate that when $N=100$ there is information in the data to estimate $\alpha$ with sufficient precision but that, contrary to SNM or LIML, GMM estimates may still be substantially biased.

The evidence from Tables 1 and 2 suggests that Hillier's basic results for ordinary and symmetrically normalized 2SLS estimators may have a wider applicability. In effect, GMM2 and SNM2, unlike 2SLS, are not only functions of the second moments of the data but also of the fourth-order moments that enter the weighting matrix of the moment conditions.

Model 1 is the leading case from the point of view that IV estimators of structural equations with predetermined instruments tend to rely on orthogonality conditions that are similar to those in Model 1.

Table 3 (p. 41) presents the results for Model 2, which makes use of the restrictions derived from Assumptions A and B. This model incorporates the quadratic orthogonality conditions given in (42). By adding the stationarity restrictions, however, the entire list of moment conditions admits a linear representation (Ahn and Schmidt 1995), so that GMM2 in Table 3 is a linear IV estimator (as proposed by Arellano and Bover 1995). All the estimators in this ta-

Table 5. Model 1: Robust Estimates, Quantiles of the $t$ Statistics

\begin{tabular}{|c|c|c|c|c|c|c|c|c|c|c|c|c|}
\hline & \multicolumn{6}{|c|}{$T=4$} & \multicolumn{6}{|c|}{$T=7$} \\
\hline & \multicolumn{3}{|c|}{$\alpha=.5$} & \multicolumn{3}{|c|}{$\alpha=.8$} & \multicolumn{3}{|c|}{$\alpha=.5$} & \multicolumn{3}{|c|}{$\alpha=.8$} \\
\hline & GMM2 & SNM2 & LIML2 & GMM2 & SNM2 & LIML2 & GMM2 & SNM2 & LIML2 & GMM2 & SNM2 & LIML2 \\
\hline \multicolumn{13}{|c|}{$\sigma_{\eta}^{2}=0$} \\
\hline .05 & -2.04 & -1.97 & -1.91 & -2.25 & -2.12 & -2.07 & -2.49 & -2.24 & -2.34 & -2.74 & -2.24 & -2.45 \\
\hline .10 & -1.61 & -1.54 & -1.47 & -1.80 & -1.62 & -1.55 & -2.01 & -1.73 & -1.82 & -2.28 & -1.79 & -1.90 \\
\hline .25 & -.87 & -.78 & -.73 & -1.00 & -.80 & -.75 & -1.22 & -.91 & -.92 & -1.47 & -.94 & -.92 \\
\hline .50 & -.11 & .01 & .06 & -.22 & .02 & .05 & -.33 & .00 & .08 & -.57 & -.03 & .09 \\
\hline .75 & .58 & .71 & .76 & .45 & .72 & .73 & .56 & .91 & 1.05 & .28 & .85 & 1.06 \\
\hline .90 & 1.18 & 1.32 & 1.35 & 1.00 & 1.28 & 1.26 & 1.30 & 1.67 & 1.89 & 1.03 & 1.62 & 1.89 \\
\hline .95 & 1.54 & 1.69 & 1.71 & 1.30 & 1.61 & 1.55 & 1.76 & 2.12 & 2.42 & 1.46 & 2.05 & 2.37 \\
\hline \multicolumn{13}{|c|}{$\sigma_{\eta}^{2}=.2$} \\
\hline .05 & -2.15 & -2.08 & -2.00 & -2.68 & -2.71 & -2.48 & -2.62 & -2.31 & -2.42 & -3.28 & -2.53 & -2.98 \\
\hline .10 & -1.71 & -1.62 & -1.55 & -2.15 & -2.02 & -1.84 & -2.11 & -1.79 & -1.86 & -2.73 & -1.97 & -2.22 \\
\hline .25 & -.93 & -.83 & -.76 & -1.28 & -1.01 & -.88 & -1.30 & -.93 & -.95 & -1.88 & -1.05 & -1.11 \\
\hline .50 & -.17 & .02 & .05 & -.43 & -.05 & .04 & -.41 & -.02 & .06 & -.97 & -.11 & .05 \\
\hline .75 & .54 & .71 & .77 & .29 & .75 & .73 & .45 & .87 & 1.04 & -.05 & .81 & 1.15 \\
\hline .90 & 1.13 & 1.31 & 1.34 & 77 & 1.32 & 1.15 & 1.24 & 1.68 & 1.90 & .70 & 1.60 & 2.01 \\
\hline .95 & 1.44 & 1.65 & 1.66 & .98 & 1.76 & 1.37 & 1.69 & 2.13 & 2.44 & 1.13 & 2.06 & 2.46 \\
\hline \multicolumn{13}{|c|}{$\sigma_{\eta}^{2}=1$} \\
\hline .05 & -2.36 & -2.35 & -2.26 & -3.17 & -4.44 & -3.01 & -2.76 & -2.41 & -2.55 & -3.82 & -3.10 & -3.72 \\
\hline .10 & -1.83 & -1.78 & -1.67 & -2.58 & -3.22 & -2.26 & -2.27 & -1.88 & -1.96 & -3.26 & -2.37 & -2.77 \\
\hline .25 & -1.09 & -.95 & -.82 & -1.68 & -1.67 & -1.14 & -1.44 & -.98 & -1.01 & -2.35 & -1.31 & -1.39 \\
\hline .50 & -.25 & -.05 & .03 & -.78 & -.33 & .00 & -.56 & -.05 & .03 & -1.37 & -.19 & .00 \\
\hline .75 & .46 & .73 & .77 & .01 & .70 & .70 & .32 & .87 & 1.07 & -.43 & .82 & 1.26 \\
\hline .90 & .98 & 1.31 & 1.30 & .50 & 1.51 & 1.11 & 1.09 & 1.66 & 1.94 & .35 & 1.68 & 2.14 \\
\hline .95 & 1.28 & 1.63 & 1.56 & .70 & 2.52 & 1.40 & 1.51 & 2.11 & 2.46 & .76 & 2.14 & 2.59 \\
\hline
\end{tabular}

NOTE: See note to Table 4 
Table 6. Employment Equations: Robust Estimates From the U.K. Sample

\begin{tabular}{|c|c|c|c|c|c|c|c|}
\hline \multirow{2}{*}{$\begin{array}{l}\text { Independent } \\
\text { variables }\end{array}$} & \multicolumn{4}{|c|}{ Model A } & \multicolumn{3}{|c|}{ Model B } \\
\hline & GMM2 & SNM2 & LIML2 & Indirect $G M M 2^{*}$ & GMM2 & SNM2 & $L I M L 2$ \\
\hline$\Delta n_{i(t-1)}$ & $\begin{array}{c}.800 \\
(.048)\end{array}$ & $\begin{array}{l}1.596 \\
(.105)\end{array}$ & $\begin{array}{l}1.900 \\
(.173)\end{array}$ & 1.214 & $\begin{array}{c}.825 \\
(.056)\end{array}$ & $\begin{array}{c}2.186 \\
(.216)\end{array}$ & $\begin{array}{l}.836 \\
(.060)\end{array}$ \\
\hline$\Delta n_{i(t-2)}$ & $\begin{array}{c}-.116 \\
(.021)\end{array}$ & $\begin{array}{c}-.384 \\
(.045)\end{array}$ & $\begin{array}{l}.105 \\
(.053)\end{array}$ & -.282 & $\begin{array}{c}-.074 \\
(.020)\end{array}$ & $\begin{array}{c}-.455 \\
(.077)\end{array}$ & $\begin{array}{c}.344 \\
(.038)\end{array}$ \\
\hline$\Delta w_{i t}$ & $\begin{array}{c}-.640 \\
(.054)\end{array}$ & $\begin{array}{r}-1.897 \\
(.160)\end{array}$ & $\begin{array}{r}.507 \\
(.224)\end{array}$ & -4.638 & & & \\
\hline$\Delta w_{i(t-1)}$ & $\begin{array}{c}.564 \\
(.066)\end{array}$ & $\begin{array}{l}2.138 \\
(.142)\end{array}$ & $\begin{array}{c}.487 \\
(.222)\end{array}$ & 1.567 & $\begin{array}{c}.431 \\
(.076)\end{array}$ & $\begin{array}{l}2.841 \\
(.312)\end{array}$ & $\begin{array}{l}.615 \\
(.080)\end{array}$ \\
\hline$\Delta k_{i t}$ & $\begin{array}{c}.219 \\
(.051)\end{array}$ & $\begin{array}{c}.238 \\
(.089)\end{array}$ & $\begin{array}{r}-1.353 \\
(.198)\end{array}$ & .604 & & & \\
\hline$\Delta k_{i(t-1)}$ & & & & & $\begin{array}{c}-.077 \\
(.045)\end{array}$ & $\begin{array}{c}-.787 \\
(.126)\end{array}$ & $\begin{array}{c}-.235 \\
(.049)\end{array}$ \\
\hline$\Delta y s_{i t}$ & $\begin{array}{c}.890 \\
(.098)\end{array}$ & $\begin{array}{l}1.747 \\
(.204)\end{array}$ & $\begin{array}{c}.674 \\
(.228)\end{array}$ & 3.105 & & & \\
\hline$\Delta y s_{i(t-1)}$ & $\begin{array}{c}-.874 \\
(.105)\end{array}$ & $\begin{array}{r}-2.897 \\
(.229)\end{array}$ & $\begin{array}{r}-.006 \\
(.312)\end{array}$ & -4.101 & $\begin{array}{c}-.115 \\
(.100)\end{array}$ & $\begin{array}{r}-2.438 \\
(.358)\end{array}$ & $\begin{array}{c}-.427 \\
(.112)\end{array}$ \\
\hline$\Delta y s_{i(t-2)}$ & & & & & $\begin{array}{c}.095 \\
(.091)\end{array}$ & $\begin{array}{l}1.511 \\
(.266)\end{array}$ & $\begin{array}{c}.126 \\
(.101)\end{array}$ \\
\hline Sargan test (df) & $63.0(50)$ & $67.1(50)$ & $44.5(50)$ & $62.8(50)$ & $68.3(51)$ & $66.5(51)$ & $57.8(51)$ \\
\hline & & & & & & & \\
\hline $\begin{array}{l}\Delta n_{j(t-1)} \\
\Delta w_{i t}\end{array}$ & $\begin{array}{l}.271 \\
.193\end{array}$ & & & & .269 & & \\
\hline$\Delta w_{i(t-1)}$ & .309 & & & & & & \\
\hline$\Delta k_{i t}$ & .108 & & & & .289 & & \\
\hline$\Delta k_{i(t-1)}$ & & & & & .158 & & \\
\hline
\end{tabular}

* Dependent variable is $\Delta w_{i t}$.

NOTE: The dependent variable is $\Delta n_{t t}$. The sample period is 1979-1984 (140 companies). Time dummies are included in all equations. Asymptotic standard errors robust to heteroscedasticity

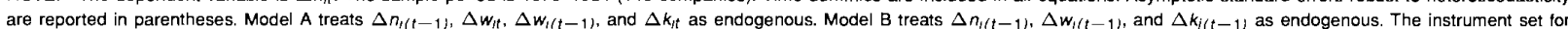
Models $A$ and $B$ includes lags of employment dated $(t-2)$ and earlier, lags of wages and capital dated $(t-2)$ and $(t-3)$, and the levels and first difterences of firm real sales and firm real stocks dated $\langle t-2)$. The instrument set for all the AR(2) models includes lags of employment dated ( $t-2)$ and earlier, and for those in the first three columns also lags of wages dated $(t-2)$ and earlier The $R^{2}$ 's for the IV's denote the partial $R^{2}$ between the instruments and each endogenous explanatory variable once the exogenous variables included in the equation have been partialled out.

ble exhibit small median biases and dispersions, although when there is a difference in MAE it favors the MDE. The differences between GMM2, SNM2, and LIML2 are small in most cases without a clear pattern in the relation, except for the fact that LIML2 tended to have a smaller bias and it was the estimator with the highest dispersion in all the experiments.

Both GMM2 and SNM2 are two-step estimators based on one-step GMM residuals that use all the orthogonality conditions from Model 2, and the inverse of the second moments of the instruments as the weighting matrix. Notice that this one-step estimator is not asymptotically efficient, not even under classical errors. From calculations based on alternative residuals (not reported), we found that the results for GMM2 and SNM2 were sensitive to the choice of onestep residuals, an issue which does not arise for LIML2 or MDE because they are calculated in one step. (We obtained results for GMM2 and SNM2 estimates based on GMM1 residuals from Model 1 and one-step residuals from Model 2 , but using an identity as the weighting matrix. As expected, the impact of using Model 1 residuals was more important when Model 1 estimates were highly imprecise.)

Table 7. Employment Equations: Robust Estimates From the U.K. Sample

\begin{tabular}{|c|c|c|c|c|c|c|}
\hline \multirow{2}{*}{$\begin{array}{l}\text { Independent } \\
\text { variables }\end{array}$} & \multicolumn{6}{|c|}{$A R(2)$ Models } \\
\hline & GMM2 & SNM2 & LIML2 & GMM2 & SNM2 & $L I M L 2$ \\
\hline$\Delta n_{j(t-1)}$ & $\begin{array}{c}.691 \\
(.051)\end{array}$ & $\begin{array}{l}1.635 \\
(.074)\end{array}$ & $\begin{array}{l}1.412 \\
(.067)\end{array}$ & $\begin{array}{c}.320 \\
(.053)\end{array}$ & $\begin{array}{c}.827 \\
(.065)\end{array}$ & $\begin{array}{c}.092 \\
(.047)\end{array}$ \\
\hline$\Delta n_{i(t-2)}$ & $\begin{array}{r}-.114 \\
(.026)\end{array}$ & $\begin{array}{r}-.439 \\
(.039)\end{array}$ & $\begin{array}{c}-.348 \\
(.025)\end{array}$ & $\begin{array}{c}.022 \\
(.022)\end{array}$ & $\begin{array}{c}-.094 \\
(.032)\end{array}$ & $\begin{array}{l}.218 \\
(.019)\end{array}$ \\
\hline$\Delta w_{i(t-1)}$ & $\begin{array}{c}.598 \\
(.070)\end{array}$ & $\begin{array}{l}1.958 \\
(.095)\end{array}$ & $\begin{array}{c}.297 \\
(.073)\end{array}$ & & & \\
\hline$\Delta w_{i(t-2)}$ & $\begin{array}{c}.013 \\
(.036)\end{array}$ & $\begin{array}{c}-.075 \\
(.053)\end{array}$ & $\begin{array}{c}-.163 \\
(.041)\end{array}$ & & & \\
\hline Sargan test (df) & $65.9(50)$ & $71.3(50)$ & $48.8(50)$ & $32.8(25)$ & $31.3(25)$ & $31.7(25)$ \\
\hline \multicolumn{7}{|c|}{$R^{2}$ 's for IV's } \\
\hline$\Delta n_{i(t-1)}$ & .216 & & & .152 & & \\
\hline
\end{tabular}

NOTE: See note to Table 6. 
Finally, it is possible to make comparisons across tables. The interquartile ranges become smaller if we move from Tables 1 and 2 to Table 3. Indeed, the efficiency gains from enforcing stationarity restrictions are always substantial for all the estimators, but they are particularly important in the cases with $\alpha=.8$ and $\sigma_{\eta}^{2}=.2$ or 1 .

We also investigated the finite-sample distributions of the standardized one- and two-step GMM, SNM and LIML " $t$ statistics" for Model 1 of the form $t=\hat{v}^{-1 / 2}(\hat{\alpha}-$ $\alpha$ ), where $\hat{\alpha}$ is an estimator and $\hat{v}$ is the corresponding estimated asymptotic variance. The $t$ statistics are asymptotically $\mathrm{N}(0,1)$. Because the usual tests of hypotheses and confidence intervals rely on this approximation, it is useful to check the accuracy of the approximation for the sample sizes and parameter values considered previously.

Tables 4 and 5 (pp. 42-43) report finite-sample quantiles of the $t$ statistics based on 10,000 replications for nonrobust and robust estimates, respectively. We use a larger number of replications because in this case the .90 and .95 quantiles in the upper tail of the distribution are of special interest. The median shows that the distributions of the GMM $t$ statistics are shifted to the left, with the absolute value of the shift increasing with $\alpha, \sigma_{\eta}^{2}$, and $T$. In contrast, the dis- tributions of the SNM and LIML $t$ statistics are centered at values that are most of the time very close to 0 . Turning to the .90 and .95 quantiles, when $T=4$ the differences with the corresponding $\mathrm{N}(0,1)$ quantiles are always smaller for the SNM and LIML $t$ statistics than for the GMM, sometimes by a wide margin. This is true for both nonrobust and robust $t$ ratios, although the latter show higher interquantile ranges. When $T=7$, the contrast between robust and nonrobust $t$ ratios becomes more marked. Although the normal approximation works reasonably well for SNM1 and LIML1, the distributions of SNM2 and LIML2 exhibit thick tails. The distributions of the GMM $t$ ratios with $T=7$ remain skewed, but whereas the .95 quantiles are very low for GMM1, those for GMM2 tend to be closer to the normal values than those from SNM2 or LIML2.

\section{EMPIRICAL ILLUSTRATIONS}

Our first illustration of the previous methods proceeds by reestimating the employment equations presented by Arellano and Bond (1991) using symmetrically normalized and indirect GMM estimators. The Arellano-Bond dataset consists of an unbalanced panel of 140 quoted companies from the United Kingdom, whose main activity is manufacturing and for which seven, eight, or nine continuous annual

Table 8. VAR Estimates for Employment and Wage Equations From the Spanish Sample

\begin{tabular}{|c|c|c|c|c|c|c|}
\hline \multirow{2}{*}{$\begin{array}{l}\text { Independent } \\
\text { variables }\end{array}$} & \multicolumn{6}{|c|}{ "Model f" restrictions } \\
\hline & GMM2 & SNM2 & LIML2 & GMM2 & SNM2 & LIML2 \\
\hline \multicolumn{7}{|c|}{$\Delta n_{i t}$ equation } \\
\hline$\Delta n_{i(t-1)}$ & $\begin{array}{c}.842 \\
(.669 ; 1.015) \\
{[.712 ; 1.209]}\end{array}$ & $\begin{array}{c}1.087 \\
(.894 ; 1.280) \\
{[.959 ; 1.485]}\end{array}$ & $\begin{array}{c}1.004 \\
(.830 ; 1.178)\end{array}$ & $\begin{array}{c}.748 \\
(.575 ; .921) \\
{[.505 ; .976]}\end{array}$ & $\begin{array}{c}.813 \\
(.636 ; .988) \\
{[.629 ; 1.092]}\end{array}$ & $\begin{array}{c}.832 \\
(.661 ; 1.002)\end{array}$ \\
\hline$\Delta n_{i(t-2)}$ & $\begin{array}{c}-.003 \\
(-.060 ; .054) \\
{[-.146 ; .028]}\end{array}$ & $\begin{array}{c}-.074 \\
(-.140 ;-.008) \\
{[-.244 ;-.039]}\end{array}$ & $\begin{array}{c}-.049 \\
(-.110 ; .012)\end{array}$ & $\begin{array}{c}.038 \\
(-.005 ; .081) \\
{[-.027 ; .084]}\end{array}$ & $\begin{array}{c}.030 \\
(-.015 ; .075) \\
{[-.046 ; .073]}\end{array}$ & $\begin{array}{c}.027 \\
(-.018 ; .072)\end{array}$ \\
\hline$\Delta w_{i(t-1)}$ & $\begin{array}{c}.078 \\
(-.086 ; .242) \\
{[-.006 ; .412]}\end{array}$ & $\begin{array}{c}.222 \\
(.046 ; .398) \\
{[.124 ; .624]}\end{array}$ & $\begin{array}{c}.177 \\
(.016 ; .338)\end{array}$ & & & \\
\hline$\Delta w_{i(t-2)}$ & $\begin{array}{c}-.053 \\
(-.102 ;-.004) \\
{[-.116 ;-.002]}\end{array}$ & $\begin{array}{c}-.074 \\
(-.127 ;-.021) \\
{[-.138 ;-.020]}\end{array}$ & $\begin{array}{c}-.068 \\
(-.121 ;-.015)\end{array}$ & & & \\
\hline Sargan test (df) & $36.9(36)$ & $37.2(36)$ & $35.5(36)$ & $14.4(18)$ & $13.5(18)$ & $13.0(18)$ \\
\hline \multicolumn{7}{|c|}{$R^{2}$ 's for IV's } \\
\hline $\begin{array}{l}\Delta n_{i(t-1)} \\
\Delta w_{i(t-1)}\end{array}$ & $\begin{array}{l}.033 \\
.031\end{array}$ & & & .022 & & \\
\hline \multicolumn{7}{|c|}{$\Delta w_{i t}$ equation } \\
\hline$\Delta w_{i(t-1)}$ & $\begin{array}{c}.178 \\
(-.042 ; .398) \\
{[-.075 ; .405]}\end{array}$ & $\begin{array}{c}.228 \\
(-.008 ; .464) \\
{[-.100 ; .482]}\end{array}$ & $\begin{array}{c}.063 \\
(-.176 ; .302)\end{array}$ & $\begin{array}{c}.178 \\
(-.042 ; .398) \\
{[-.144 ; .429]}\end{array}$ & $\begin{array}{c}.228 \\
(-.008 ; .464) \\
{[-.232 ; .519]}\end{array}$ & $\begin{array}{c}.063 \\
(-.176 ; .302)\end{array}$ \\
\hline$\Delta w_{i(t-2)}$ & $\begin{array}{c}-.012 \\
(-.081 ; .049) \\
{[-.076 ; .042]}\end{array}$ & $\begin{array}{c}-.002 \\
(-.066 ; .062) \\
{[-.077 ; .052]}\end{array}$ & $\begin{array}{c}-.039 \\
(-.102 ; .024)\end{array}$ & $\begin{array}{c}-.012 \\
(-.081 ; .049) \\
{[-.089 ; .045]}\end{array}$ & $\begin{array}{c}-.002 \\
(-.066 ; .062) \\
{[-.100 ; .060]}\end{array}$ & $\begin{array}{c}-.039 \\
(-.102 ; .024)\end{array}$ \\
\hline Sargan test (df) & $12.7(18)$ & $12.9(18)$ & $12.2(18)$ & $12.7(18)$ & $12.9(18)$ & $12.2(18)$ \\
\hline \multicolumn{7}{|c|}{$R^{2}$ 's for IV's } \\
\hline$\Delta w_{i(t-1)}$ & .019 & & & & & \\
\hline
\end{tabular}

NOTE: The sample period is 1983-1990 (738 companies). Time dummies are included in all equations. The instrument set for all the employment equations includes lags of employment dated $(t-2)$ and earlier, and for those in the first three columns also lags of wages dated $(t-2)$ and earlier. The instrument set for the wage equation includes lags of wages dated $(t-2)$ and earlier. The $R^{2}$ 's for the IV's denote the partial $R^{2}$ between the instruments and each endogenous explanatory variable once the exogenous variables included in the equation have been partialled out. $95 \%$ asymptotic confidence intervals based on heteroscedasticity-robust standard errors are in parentheses; $95 \%$ moment-restricted bootstrap confidence intervals are in brackets. The bootstrap confidence intervals for the equations in the first three columns are based on a distribution that satisfies a larger set of moment conditions than those in the last three columns. The reason is that the former include lagged wages as instruments for the employment equation, which are absent from the latter. 
observations are available for the period 1976-1984. The models are all log-linear relationships between the number of employees, the average real wage, the stock of capital, a measure of industry output, lagged values of the previous variables, time dummies, and company effects. The reader is referred to the Arellano and Bond article for a detailed description of the models and the data.

Table 6 (pp. 44) contains the results for two different models estimated in first differences using IV's. Model A includes contemporaneous wage and capital variables, which are treated as endogenous along with the first lag of employment. In this model, lagged sales and stocks are used as outside instruments in addition to lags of the endogenous variables included in the equation. Model B only includes lagged values of wages and capital, and it could be interpreted as an approximated Euler equation for employment with quadratic adjustment costs. Columns labeled GMM2 reproduce some of the results obtained by Arellano and Bond. The SNM2 and LIML2 estimates are calculated as described in Section 1, and for Model A there is an additional column containing indirect GMM2 estimates that were obtained by normalizing to unity the coefficient of contemporaneous wages. Finally, Table 7 (p. 44) presents GMM2, SNM2, and LIML2 estimates of some simple second-order autoregressive [AR(2)] models for employment with and without the inclusion of lagged wages.

As Tables 6 and 7 show, SNM2, LIML2 and indirect GMM2 estimates are mostly far apart from the direct GMM2 estimates. These results uncover the fact that the GMM2 estimates from the dataset of U.K. firms are probably much less reliable than what their estimated asymptotic standard errors would suggest.

Our second empirical illustration is based on a similar but larger balanced panel of 738 Spanish manufacturing companies, for which there are available annual observations for the period 1983-1990 (see the Appendix for a description of these data). We consider a bivariate VAR model for the logarithms of employment and wages. The employment equation contains both lagged employment and lagged wages, but the wage equation only includes its own lags. This model can be regarded as the reduced form of an intertemporal model of employment determination under rational expectations (see Sargent 1978). To obtain the reduced form, an $\mathrm{AR}(2)$ process for $\log$ wages is assumed, and the Euler equation in the log of employment for the optimal contingency plans is solved.

Table 8 (p. 45) presents GMM2, SNM2, and LIML2 estimates of the two equations, using only lagged variables in levels as instruments for equations in first-differences (the basic set of moment conditions that we called "Model 1"), and Table 9 contains the estimates that add lagged variables in first-differences as instruments for equations in levels (i.e., including the stationarity restrictions of "Model 2"). We also report estimates of a univariate $\operatorname{AR}(2)$ process for employment for the two models (nonrobust estimates are not reported but are available on request).

In addition to asymptotic confidence intervals, for GMM2 and SNM2 we calculated $95 \%$ semiparametric bootstrap confidence intervals based on 1,000 replications from the empirical distribution function of the data subject to the moment restrictions (Back and Brown 1993). Following Brown and Newey (1992), we drew the bootstrap samples from the mass-point distribution that estimated the probability of the $i$ th observation as $\hat{p}_{i}=1 /[1+$ $\left.\hat{\mu}^{\prime} \psi\left(y_{i}, \hat{\delta}\right)\right] N$, where

$$
\hat{\mu}=\arg \min _{\mu} N^{-1} \sum_{i=1}^{N} \log \left[1+\mu^{\prime} \psi\left(y_{i}, \hat{\delta}\right)\right]^{2}
$$

and $\psi\left(y_{i}, \hat{\delta}\right)$ is the vector of orthogonality conditions for observation $i$ evaluated at the appropriate parameter estimates. (We were unable to obtain bootstrap confidence intervals for LIML2 due to computing limitations, because each evaluation of LIML2 required numerical optimization over a larger parameter space including time dummies.)

Table 8 (p. 45) contains some interesting results. GMM2 estimates of Model 1 are still different from SNM2 and LIML2 estimates but by a smaller margin than the corresponding estimates for the U.K. panel. The differences become even smaller for the univariate employment estimates that are based on half the number of moments used for the estimates in the first three columns. On the other hand, the estimates of Model 2 in Table 9 appear to be more precise, presumably because the additional orthogonality conditions are highly informative. In this case, GMM2 and SNM2 estimates provide very similar results. The Sargan statistics,

\begin{tabular}{|c|c|c|c|}
\hline \multirow{2}{*}{$\begin{array}{l}\text { Independent } \\
\text { variables }\end{array}$} & \multicolumn{3}{|c|}{ "Model 2" restrictions } \\
\hline & GMM2 & SNM2 & LIML2 \\
\hline \multicolumn{4}{|c|}{$\Delta n_{i t}$ equation } \\
\hline$\Delta n_{i(t-1)}$ & $\begin{array}{c}1.163 \\
(1.112 ; 1.214) \\
{[1.132 ; 1.218]}\end{array}$ & $\begin{array}{c}1.208 \\
(1.137 ; 1.279) \\
{[1.143 ; 1.229]}\end{array}$ & $\begin{array}{c}1.624 \\
(1.424 ; 1.824)\end{array}$ \\
\hline$\Delta n_{i(t-2)}$ & $\begin{array}{c}-.135 \\
(-.172 ;-.098) \\
{[-.197 ;-.108]}\end{array}$ & $\begin{array}{c}-.142 \\
(-.185 ;-.099) \\
{[-.206 ;-.117]}\end{array}$ & $\begin{array}{c}-.160 \\
(-.231 ;-.089)\end{array}$ \\
\hline$\Delta w_{i(t-1)}$ & $\begin{array}{c}.121 \\
(.086 ; .156) \\
{[.091 ; .161]}\end{array}$ & $\begin{array}{c}.116 \\
(.077 ; .155) \\
{[.094 ; .164]}\end{array}$ & $\begin{array}{c}.058 \\
(-.001 ; .117)\end{array}$ \\
\hline$\Delta w_{i(t-2)}$ & $\begin{array}{c}-.132 \\
(-.171 ;-.093) \\
{[-.173 ;-.101]}\end{array}$ & $\begin{array}{c}-.151 \\
(-.194 ;-.108) \\
{[-.177 ;-.101]}\end{array}$ & $\begin{array}{c}-.242 \\
(-.313 ;-.171)\end{array}$ \\
\hline Sargan test (df) & $80.1(48)$ & $69.1(48)$ & $50.3(48)$ \\
\hline \multicolumn{4}{|c|}{$\Delta w_{i t}$ equation } \\
\hline$\Delta w_{i(t-1)}$ & $\begin{array}{c}.854 \\
(.815 ; .893) \\
{[.825 ; .902]}\end{array}$ & $\begin{array}{c}.873 \\
(.834 ; .912) \\
{[.828 ; .905]}\end{array}$ & $\begin{array}{c}.869 \\
(.828 ; .911)\end{array}$ \\
\hline$\Delta w_{i(t-2)}$ & $\begin{array}{c}.152 \\
(.105 ; .199) \\
{[.099 ; .186]}\end{array}$ & $\begin{array}{c}.138 \\
(.089 ; .187) \\
{[.094 ; .183]}\end{array}$ & $\begin{array}{c}.141 \\
(.090 ; .192)\end{array}$ \\
\hline Sargan test (df) & $71.4(24)$ & $72.2(24)$ & $71.4(24)$ \\
\hline
\end{tabular}

NOTE: The sample period is 1983-1990 (738 companies). Time dummies are included in al equations. The instrument set for the employment equations includes lags of employment and wages dated $(t-2)$ and earlier for errors in first differences, and lags of employment and wage wa firs diferences dat $(t-1)$ lor erors in levels. The instument set for the wage equations is similar, but excludes lagged employment in levels and first differences. GMM2 and SNM2 are two-step estimates based on one-step GMM residuals that use all the orthogonality restrictions from Model 2 and the inverse of the second moments of the instruments as the weighting matrix. $95 \%$ asymptotic confidence intervals based on heteroscedasticty-robust standard errors are in parentheses; $95 \%$ moment-restricted bootstrap confidence intervals are in brackets. 
Table 10. VAR Estimates for Employment and Wage Equations From the Spanish Sample

\begin{tabular}{|c|c|c|c|c|c|c|}
\hline $\begin{array}{l}\text { Independent } \\
\text { variables }\end{array}$ & GMM2 & SNM2 & LIML2 & GMM2 & SNM2 & $L I M L 2$ \\
\hline \multicolumn{7}{|c|}{$\Delta n_{i t}$ equation } \\
\hline$\Delta n_{i(t-1)}$ & $\begin{array}{c}.788 \\
(.610 ; .966) \\
{[.528 ; 1.248]}\end{array}$ & $\begin{array}{c}1.160 \\
(.888 ; 1.432) \\
{[.932 ; 1.903]}\end{array}$ & $\begin{array}{c}1.002 \\
(.777 ; 1.227)\end{array}$ & $\begin{array}{c}.441 \\
(.167 ; .715) \\
{[.217 ; 0.983]}\end{array}$ & $\begin{array}{c}.815 \\
(.509 ; 1.121) \\
{[.424 ; 1.214]}\end{array}$ & $\begin{array}{c}1.517 \\
(1.081 ; 1.952)\end{array}$ \\
\hline$\Delta n_{i(t-2)}$ & $\begin{array}{c}-.042 \\
(-.109 ; .025) \\
{[-.265 ;-.008]}\end{array}$ & $\begin{array}{c}-.206 \\
(-.306 ;-.106) \\
{[-.567 ;-.120]}\end{array}$ & $\begin{array}{c}-.181 \\
(-.271 ;-.091)\end{array}$ & $\begin{array}{c}.063 \\
(.002 ; .124) \\
{[-.060 ; .120]}\end{array}$ & $\begin{array}{c}.003 \\
(-.062 ; .069) \\
{[-.138 ; .090]}\end{array}$ & $\begin{array}{c}-.170 \\
(-.268 ;-.072)\end{array}$ \\
\hline$\Delta w_{i(t-1)}$ & $\begin{array}{c}.337 \\
(.151 ; .523) \\
{[.099 ; .680]}\end{array}$ & $\begin{array}{c}.650 \\
(.371 ; .929) \\
{[.300 ; 1.048]}\end{array}$ & $\begin{array}{c}.675 \\
(.452 ; .898)\end{array}$ & & & \\
\hline$\Delta w_{i(t-2)}$ & $\begin{array}{c}.001 \\
(-.065 ; .067) \\
{[-.150 ; .059]}\end{array}$ & $\begin{array}{c}-.040 \\
(-.120 ; .040) \\
{[-.261 ; .006]}\end{array}$ & $\begin{array}{c}-.018 \\
(-.098 ; .062)\end{array}$ & & & \\
\hline Sargan test (df) & $30.2(36)$ & $23.0(36)$ & $24.8(36)$ & $23.3(18)$ & $24.3(18)$ & $16.5(18)$ \\
\hline \multicolumn{7}{|c|}{$R^{2}$ 's for IV's: } \\
\hline $\begin{array}{l}\Delta n_{i(t-1)} \\
\Delta w_{i(t-1)}\end{array}$ & $\begin{array}{l}.064 \\
.080\end{array}$ & \multicolumn{5}{|c|}{.040} \\
\hline \multicolumn{7}{|c|}{$\Delta w_{i t}$ Equation } \\
\hline$\Delta w_{i(t-1)}$ & $\begin{array}{c}-.612 \\
(-.984 ;-.240) \\
{[-.962 ; .359]}\end{array}$ & $\begin{array}{c}-1.198 \\
(-1.442 ;-.953) \\
{[-3.512 ; 2.492]}\end{array}$ & $\begin{array}{c}-1.246 \\
(-1.509 ;-.983)\end{array}$ & $\begin{array}{c}-.612 \\
(-.984 ;-.240) \\
{[-.954 ; .402]}\end{array}$ & $\begin{array}{c}-1.198 \\
(-1.442 ;-.953) \\
{[-4.893 ; 4.932]}\end{array}$ & $\begin{array}{c}-1.246 \\
(-1.509 ;-.983)\end{array}$ \\
\hline$\Delta w_{i(t-2)}$ & $\begin{array}{c}-.120 \\
(-.231 ;-.009) \\
{[-.232 ; .102]}\end{array}$ & $\begin{array}{c}-.270 \\
(-.349 ;-.191) \\
{[-.627 ; .348]}\end{array}$ & $\begin{array}{c}-.231 \\
(-.319 ;-.143)\end{array}$ & $\begin{array}{c}-.120 \\
(-.231 ;-.009) \\
{[-.239 ; .183]}\end{array}$ & $\begin{array}{c}-.270 \\
(-.349 ;-.191) \\
{[-1.202 ; .993]}\end{array}$ & $\begin{array}{c}-.231 \\
(-.319 ;-.143)\end{array}$ \\
\hline Sargan test (df) & $17.3(18)$ & $11.0(18)$ & $9.3(18)$ & $17.3(18)$ & $11.0(18)$ & $9.3(18)$ \\
\hline \multicolumn{7}{|c|}{$R^{2}$ 's for $I V ' s$} \\
\hline$\Delta w_{i(t-1)}$ & .023 & & & & & \\
\hline
\end{tabular}

NOTE: The sample period is $1983-1990$ (random subsample of 200 companies). See note to Table 8 .

however, indicate a clear rejection of the stationarity restrictions in both the employment and the wage equations. It is also noticeable that, although bootstrap confidence intervals are always larger than the asymptotic confidence intervals, the differences between the two are generally small. As for the LIML2 parameter estimates and Sargan statistics, they are similar to GMM2 and SNM2 for the wage equation but somewhat different for the employment equation. In particular, the first lagged employment coefficient estimate is higher, and the Sargan statistic turns out to be much smaller than those for the other estimators.

We reestimated Model 1 with a random subsample of 200 firms, which is similar to the size of the U.K. sample. Interestingly, some of the results (reported in Table 10) are closer to the U.K. results for similar specifications than those based on the full Spanish sample. In particular, the SNM2 estimates of the AR(2) model for employment are remarkably stable over the three datasets, but standard GMM2 estimates would be seriously downward biased in the smaller samples. Moreover, the discrepancies between asymptotic and bootstrap confidence intervals in the random subsample were greater than in the full sample. (Bootstrap standard errors for the U.K. unbalanced panel were not calculated because they would depend on a nontrivial specification of the empirical distribution function for the unbalanced observations.) In contrast, perhaps as a result of a higher probability of outliers in small samples, the LIML2 estimate of the leading coefficient in the AR(2) model for employment was a very small number in the U.K. sample and a very large one in the Spanish subsample of 200 firms, whereas it was similar to SNM2 for the full Spanish sample.

Finally, we simulated data as close as possible to the $\operatorname{AR}(2)$ employment equation to see if the findings that we obtained with the subsample of 200 companies were substantiated in the Monte Carlo simulations. Random errors and individual effects were generated from independent normal distributions with variances equal to the values estimated from the SNM2 residuals of the full Spanish sample. Because the estimated time effects showed very little variability, the constant was set to a common value for all periods given by the average estimated time effect in levels, although the estimates in the simulations included time dummies. As a consequence the model was stationary, and we generated (and discarded) 100 preliminary observations for each individual to minimize the impact of initial conditions. The results for GMM2 and SNM2 are reported in Table 11 and confirm the impression conveyed by the real data (unfortunately, we were unable to simulate LIML2 due to computing limitations). The SNM2 estimates are almost median unbiased, but GMM2 shows large downward biases, especially when $N=200$. A comparison in terms of MAE's also favors SNM2 for both sample sizes and parameter estimates. Last, looking at the quantiles of the $t$ ratios shown in the lower panel of Table 11, it appears that the $\mathrm{N}(0,1)$ approximation is reasonable for the SNM $t$ ratios but not for the GMM $t$ ratios. 
Table 11. Monte Carlo Simulations for the $A R(2)$ Model for Employment

\begin{tabular}{|c|c|c|c|c|c|}
\hline & & \multicolumn{2}{|c|}{$N=738$} & \multicolumn{2}{|c|}{$N=200$} \\
\hline & & GMM2 & SNM2 & GMM2 & SNM2 \\
\hline \multicolumn{6}{|c|}{ Summary of estimates } \\
\hline \multirow[t]{5}{*}{$\alpha_{1}$} & Median & .72 & .82 & .55 & .82 \\
\hline & $\%$ bias & 12.0 & .3 & 32.2 & .8 \\
\hline & iqr & .14 & .15 & .27 & .28 \\
\hline & iq80 & .28 & .29 & .56 & .61 \\
\hline & MAE & .11 & .08 & .26 & .14 \\
\hline \multirow[t]{5}{*}{$\alpha_{2}$} & Median & .01 & .03 & -.02 & .02 \\
\hline & $\%$ bias & 64.6 & 7.0 & 163.3 & 35.4 \\
\hline & iqr & .04 & .04 & .06 & .08 \\
\hline & iq80 & .07 & .07 & .11 & .14 \\
\hline & MAE & .02 & .02 & .05 & .04 \\
\hline \multicolumn{6}{|c|}{ Quantiles of the $t$ statistics } \\
\hline \multirow[t]{5}{*}{$\alpha_{1}$} & .10 & -2.44 & -1.37 & -3.61 & -1.62 \\
\hline & .25 & -1.75 & -.74 & -2.77 & -.82 \\
\hline & .50 & -1.01 & .02 & -1.84 & .04 \\
\hline & .75 & -.25 & .77 & -.97 & .81 \\
\hline & .90 & .41 & 1.33 & -.21 & 1.42 \\
\hline \multirow[t]{5}{*}{$\alpha_{2}$} & .10 & -2.22 & -1.55 & -2.93 & -1.92 \\
\hline & .25 & -1.48 & -.82 & -2.16 & -1.05 \\
\hline & .50 & -.78 & -.08 & -1.26 & -.24 \\
\hline & .75 & -.01 & .60 & -.45 & .60 \\
\hline & .90 & .62 & 1.19 & .17 & 1.08 \\
\hline
\end{tabular}

NOTE: $\alpha_{1}=813, \alpha_{2}=.030, \gamma=.777, \sigma_{\eta}^{2}=.038, \sigma_{v}^{2}=.01 .1,000$ replications. $\%$ bia gives the percentage median bias for all estimates; iqr is the 75th-25th interquartile range; iq80 is the 90th-10th interquantile range; MAE denotes the median absolute error. The 10 th, 25th, 50th 75 th, and 90 th quantiles for the standard normal distribution are, respectively, $-1.28,-.67,0$ 67 , and 1.28

\section{CONCLUSIONS}

There has recently been a renewed interest in the finitesample properties of GMM estimators in various time series and cross-sectional contexts. Several works have emphasized the role of estimated weighting matrices for the properties of the estimators in small samples, and several alternative methods have been considered (Angrist and Krueger 1995; Angrist, Imbens, and Krueger 1995; Altonji and Segal 1996; Hansen et al. 1996; Imbens 1997). In contrast, in this article we have focused on the role of normalization rules for the finite-sample properties of GMM estimators that make use of standard two-step weighting matrices. Our work is motivated by the results of Hillier (1990), who argued that the alternative normalization rules adopted by LIML and 2SLS are at the basis of their different sampling behavior. Hillier showed that symmetrically normalized 2SLS has similar finite-sample properties to those of LIML. This result is interesting because, unlike LIML, symmetrically normalized 2SLS is a GMM estimator based on structural-form moment conditions, and therefore it can be easily extended to distribution-free environments and robust statistics.

In particular, symmetrically normalized 2SLS is well suited for application to the nonstandard IV situations that arise in linear panel-data models with predetermined variables, which are the models of interest in this article. These models are typically estimated in orthogonal deviations or first-differences using all the available lags as instruments. Usually, there are many instruments available, but they are of poor quality because they tend to be only weakly cor- related with the first-differenced endogenous variables that appear in the equation.

In this article we have presented symmetrically normalized GMM (SNM) estimators for dynamic panel-data models that are asymptotically equivalent to ordinary optimal GMM estimators. A by-product of the estimation is a test statistic of overidentifying restrictions, based on a minimum eigenvalue calculation. We have also discussed the relation between robust and nonrobust SNM estimators and the LIML analogues. In our context, a nonrobust LIML analogue in orthogonal deviations is algebraically equivalent to an ordinary LIML estimator that solves a minimum eigenvalue problem. The robust LIML analogue, however, is the continuously updated GMM estimator proposed by Hansen et al. (1996), which no longer involves a simple minimum eigenvalue calculation.

We have reported Monte Carlo evidence on the performance of nonrobust and robust GMM, SNM, and LIML analogue estimates for an AR(1) model with individual effects. For this model we have considered two alternative sets of moment conditions, as discussed by Arellano and Bond (1991) and Arellano and Bover (1995). Because for these models the IV restrictions can be expressed as straightforward structures on the data covariance matrix, using these representations we have also calculated MD estimates for comparisons with the IV estimates. Our findings suggest that Hillier's basic results may have a wider applicability. In most cases, the differences in the behavior of SNM and LIML were small, and both had a smaller median bias and a larger interquartile range than GMM. The differences in dispersion with ordinary GMM were small, however, except in the almost unidentified cases.

Finally, as an empirical illustration, we have reported estimates of employment and wage equations from U.K. and Spanish firm panels. The results show that GMM estimates from the (smaller) U.K. panel can be very unreliable when the degree of overidentification is large. The results from the (larger) Spanish panel produce a closer agreement between ordinary and symmetrically normalized GMM estimates, although there is evidence that there can still be serious biases in GMM estimates. Some of these results are confirmed by simulating data as close as possible to the empirical data. Moment-restricted bootstrap confidence intervals show that asymptotic confidence intervals are often overoptimistic, and Sargan tests tend to reject the restrictions implied by the stationarity of initial conditions.

\section{ACKNOWLEDGMENTS}

We thank Richard Blundell, Stephen Bond, Gary Chamberlain, Guido Imbens, Whitney Newey, Enrique Sentana, Jim Stock, Ruey Tsay, an associate editor, three anonymous referees, and seminar audiences at Harvard, Northwestern, Nuffield College, Princeton, and University College London for valuable advice and helpful comments. An earlier version of this article was presented at the ESRC Econometric Study Group Annual Conference, Bristol, July 1994, and at the Econometric Society European Meeting in Maastricht, August 1994. The first author acknowledges research fund- 
Table A.1. Descriptive Statistics

\begin{tabular}{lccccc}
\hline \hline Variable & Mean & Median & deviation & Minimum & Maximum \\
\hline Employment & 310.4 & 124.0 & 702.4 & 10.0 & $11,004.0$ \\
Real wage & 1.86 & 1.75 & .67 & .32 & 6.66 \\
\hline
\end{tabular}

ing from a CEMFI Ph.D. scholarship and from the Spanist DGES, Grant PB95-0292.

\section{APPENDIX: DATA DESCRIPTION}

The Spanish dataset is a balanced panel of 738 manufacturing companies recorded in the database of the Bank of Spain's Central Balance Sheet Office from 1983 to 1990. This survey contains information on firms' balance sheets and other complementary information, including data on employment and total wage bill. This survey started ir 1982 with the collection of data from large companies with a tendency in subsequent years toward the addition of smaller companies. The database includes both quoted and nonquoted firms. The manufacturing firms included in this dataset represent more than $40 \%$ of the Spanish value added in manufacturing in 1985.

We selected firms reporting information during the whole period 1983-1990 that fulfilled several coherency conditions. All companies with negative values for net worth, capital stock, accumulated depreciation, accounting depreciation, labor costs, employment, sales, or output, or those whose book value of capital stock jumped by a factor greater than 3 from one year to the next were dropped from the sample. Finally, we concentrated on nonenergy manufacturing companies with a public share lower than $50 \%$.

\section{Variable Construction}

Employment. Number of employees is disaggregated into permanent employees (those with long-term contracts, and temporary employees (those with short-term contracts). Total employment is calculated as the number of permaneni employees, plus the average annual number of temporary employees (number of temporary employees during the year times the average number of weeks worked by temporary employees divided by 52 ).

Real Wage. The measure of the firm's annual average labor costs per employee is computed as the ratio of total wages and salaries (in million Spanish pesetas) to total number of employees. This measure was deflated using retail price indexes for each of the industries of the manufacturing sector (Source: Spain's Institute of National Statistics). Table A.1 shows some descriptive statistics for the employment and real-wage variables.

[Received July 1996. Revised June 1998.]

\section{REFERENCES}

Ahn, S, and Schmidt, P. (1995), "Efficient Estimation of Models for Dy $\rightarrow$ S namic Panel Data," Journal of Econometrics, 68, 5-27.

$\rightarrow$ Altonji, J., and Segal, L. (1996), "Small-Sample Bias in GMM Estimation of Covariance Structures," Journal of Business \& Economic Statistics $\rightarrow$ $14,353-366$

$\rightarrow$ Anderson, T. W. (1976), "Estimation of Linear Functional Relationships $\rightarrow$ Approximate Distributions and Connections with Simultaneous Equa- tions in Econometrics," Journal of the Royal Statistical Society, Ser. B, $38,1-20$.

Anderson, T. W., Kunitomo, N., and Sawa, T. (1982), "Evaluation of the Distribution Function of the Limited Information Maximum Likelihood Estimator," Econometrica, 50, 1009-1027.

Angrist, J. D., Imbens, G. W., and Krueger, A. (1995), "Jackknife Instrumental Variables Estimation," Technical Working Paper 172, National Bureau of Economic Research, Cambridge, MA.

Angrist, J. D., and Krueger, A. B. (1995), "Split Sample Instrumental Variables Estimates of the Return to Schooling," Journal of Business \& Economic Statistics, 13, 225-235.

$\rightarrow$ Arellano, M., and Bond, S. R. (1991), "Some Tests of Specification for Panel Data: Monte Carlo Evidence and an Application to Employment Equations," Review of Economic Studies, 58, 277-297.

Arellano, M., and Bover, O. (1995), "Another Look at the InstrumentalVariable Estimation of Error-Components Models," Journal of Econometrics, 68, 29-51.

Back, K., and Brown, D. P. (1993), "Implied Probabilities in GMM Estimators," Econometrica, 61, 971-975.

Bekker, P. A. (1994), "Alternative Approximations to the Distributions of Instrumental Variable Estimators," Econometrica, 62, 657-681.

Blundell, R., and Bond, S. (1998), "Initial Conditions and Moment Restrictions in Dynamic Panel Data Models," Journal of Econometrics, 87, 115-143.

Bound, J., Jaeger, D. A., and Baker, R. (1995), "Problems With Instrumental Variables Estimation When the Correlation Between the Instruments and the Endogenous Explanatory Variable is Weak," Journal of the American Statistical Association, 90, 443-450.

Brown, B. W., and Newey, W. K. (1992), "Bootstrapping for GMM," unpublished manuscript.

Chamberlain, G. (1982), "Multivariate Regression Models for Panel Data," Journal of Econometrics, 18, 5-46.

(1992), "Comment: Sequential Moment Restrictions in Panel Data," Joumal of Business \& Economic Statistics, 10, 20-26.

Goldberger, A. S., and Olkin, I. (1971), “A Minimum-Distance Interpretation of Limited-Information Estimation," Econometrica, 39, 635-639.

Hansen, L. P. (1982), "Large Sample Properties of Generalized Method of Moments Estimators," Econometrica, 50, 1029-1054.

$\rightarrow$ Hansen, L. P., Heaton, J., and Yaron, A. (1996), "Finite-Sample Properties of Some Alternative GMM Estimators," Journal of Business \& Economic Statistics, 14, 262-280.

Hillier, G. H. (1990), "On the Normalization of Structural Equations: Properties of Direction Estimators," Econometrica, 58, 1181-1194.

Holtz-Eakin, D., Newey, W., and Rosen, H. (1988), "Estimating Vector Autoregressions With Panel Data," Econometrica, 56, 1371-1395.

Imbens, G. (1997), "One-Step Estimators for Over-identified Generalized Method of Moments Models," Review of Economic Studies, 64, 359 383.

Keller, W, J. (1975), "A New Class of Limited-Information Estimators for Simultaneous Equation Systems," Journal of Econometrics, 3, 71-92.

$\rightarrow$ Kunitomo, N. (1980), "Asymptotic Expansions of the Distributions of Estimators in a Linear Functional Relationship and Simultaneous Equations," Journal of the American Statistical Association, 75, 693-700.

Malinvaud, E. (1970), Statistical Methods of Econometrics, Amsterdam: North-Holland.

Morimune, K. (1983), "Approximate Distributions of $k$-Class Estimators When the Degree of Overidentifiability Is Large Compared With the Sample Size," Econometrica, 51, 821-841.

Phillips, P. C. B. (1983), "Exact Small Sample Theory in the Simultaneous Equations Model," in Handbook of Econometrics (vol. I), eds. Z. Griliches and M. D. Intriligator, Amsterdam: North-Holland, pp. 449516.

$\rightarrow$ Qin, J., and Lawless, J. (1994), "Empirical Likelihood and General Estimating Equations," The Annals of Statistics, 22, 300-325.

Sargent, T. J. (1978), "Estimation of Dynamic Labor Demand Schedules Under Rational Expectations," Journal of Political Economy, 86, 1009 1044.

Staiger, D., and Stock, J. H. (1997), “Instrumental Variables Regression With Weak Instruments," Econometrica, 65, 557-586.

White, H. (1982), "Instrumental Variables Regression With Independent Observations," Econometrica, 50, 483-499. 